Euskal ikerketen aldizkaria | Revue d'études basques |

Revista de estudios vascos | Basque studies review

$14 \mid 2010$

Numéro XIV

\title{
Rudolf Trebitsch-en 1913ko Euskal grabazio Musikalak (II)
}

Inaxio López de Arana Arrieta

\section{OpenEdition \\ Journals}

Édition électronique

URL : http://journals.openedition.org/lapurdum/2285

DOI : 10.4000/lapurdum.2285

ISSN : 1965-0655

Éditeur

IKER

Édition imprimée

Date de publication : 1 octobre 2010

Pagination : 89-135

ISSN : 1273-3830

\section{Référence électronique}

Inaxio López de Arana Arrieta, «Rudolf Trebitsch-en 1913ko Euskal grabazio Musikalak (II)»,

Lapurdum [Linean], 14 | 2010, Sarean emana----an 15 septembre 2014, kontsultatu 01 mai 2019. URL http://journals.openedition.org/lapurdum/2285 ; DOI : 10.4000/lapurdum.2285 


\title{
Rudolf Trebitsch-en 1913ko Euskal grabazio Musikalak (II)
}

\author{
Inaxio LÓPEZ DE ARANA ARRIETA ${ }^{1}$
}

2004ko abenduan, artikulu bat plazaratu nuen Euskal Kultura eta Ikerketa Aldizkarian (21. zenbakia), Sancho el Sabio instituzioak egindako eskaintza onetsirik. Artikuluaren izenburua: "Rudolf Trebitsch-en 1913ko euskal grabazio musikalak". Lan hartan, ikerketa bat plazaratu nuen, Rudolf Trebitschen grabazio musikalei buruz egin nuena, urte eta erdiko lana. Baina orduko argitalpenean nahi baino datu oker gehiago zeudela-eta testua berridaztea erabaki dut, lehengo testuaren gainean behar beste zuzenketa eta zehaztapen egin nahirik. Segidan doakizue, beraz, ikerlan horren bigarren idazketa, berritua eta guztiz zuzendua.

Rudolf Trebitsch 1876an jaio zen, Austrian. Gazterik medikuntzako ikasketak egin bazituen ere, gerora antropologia, etnologia eta hizkuntzalaritza landu zituen gehienbat. Vienako Zientzietako Akademia Inperialeko kidea izan zen, eta munduan barrena ibili zen, tokian tokiko soinu-grabazioak biltzen, Vienako Fonograma Artxiboak egin nahi omen zuen diskobilduma osatzeko. Euskal Herrira ere etorri zen, 1913ko uztailaren 18an, eta uda osoa lanean eman ondoren euskararen eta euskal musikaren ale soinudun eder batzuk eraman zituen Vienara, bere sorterrira. Lehenengo Mundu Gerra hasi eta berehala, hain zuzen ere 1915ean, armadaren erietxe batera bidali zuten, sendagile-lanak egin zitzan. Hiru urte geroago, 1918ko urriaren 8an zendu zen Austriako Judendorf hirian, Graz-etik hurbil.

Lehengo mendearen hasieran, hain zuzen ere 1906tik 1913ra bitartean, Europako mendebaldeko zenbait herri zelta (Irlanda, Gales, Ingalaterra, Bretainia eta Eskozia), Laponiako inuiten tribuak (Groenlandia) eta Euskal Herria bisitatu zituen. Zazpi urte horietan 4.000 bat grabazio egitea lortu zuen. Gure egunetara etorriz, 2004ko otsailean Austriako Zientzietako Akademiaren Fonograma Artxiboak argitara eman zituen grabazio horietako asko, hiru CDtan bilduta. Dena den, "The Collections of Rudolf Trebitsch" izeneko bilduma horretan ${ }^{2}$ ez daude Trebitschek egindako euskal grabazio guztiak, grabazio musikalak -artikulu honen aztergai nagusia- proiektutik kanpo geratu baitira.

1. Euskal Filologian lizentziatua eta itzultzailea.

2. Izenburu osoa: "Tondokumente aus dem Phonogrammarchiv der Österreichischen Akademie der Wissenschaften. Gesamtausgabe der historischen Bestände 1899-1950. The Collections of Rudolf Trebitsch". SCHÜLLER, Dietrich. 
Rudolf Trebitschek bi asmo ekarri zituen Euskal Herrira: euskalki guztien grabazioak egitea eta euskal etnologiaren bilduma bat osatzea. Ederki bete zituen, eta gainera, grabazio musikalak ere egin zituen, euskal ondare musikalaren adierazle. Beraz, bada, bi motatako grabazioak lortu zituen: hizkuntza-grabazioak eta grabazio musikalak. Harako egonaldi hartan, laguntzaile asko izan zituen, mugaren bi aldeetakoak, hala nola, Julio Urkijo, Telesforo Aranzadi, Gregorio Mujika, Resurreccion Maria Azkue, Georges Lacombe eta Gabriel Roby. Ez ditugu atzendu behar, jakina, gramofonoaren aurrean berbetan, kantuan edo musika-tresnaren bat jotzen ibili ziren euskaldunak. Vienara itzuli eta urtebetera artikulu bat idatzi zuen ${ }^{3}$, gure arbaso haien artean izandako bizipenen eta egindako lanen lekukotzat.

Grabazio hauek 1913koak izanda ere, ez ditugu zaharrenak euskarazko lekukotasun soinudunetan, Léon Azoulay-k 1900eko Pariseko Erakusketa Unibertsalean egindakoak zaharragoak baitira ${ }^{4}$, baina esan beharrik ez dago leku aparta merezi dutela euskal kulturaren baitan.

Euskal hizkuntzaren grabazioak Vienako Fonograma Artxiboan daude, Trebitschek berak han utzi zituelako 1913an, baina 1984tik Bilboko Azkue bibliotekan eskuragarri ditugu haien kopiak, José $\mathrm{M}^{a}$ Etxebarria euskaltzainari esker. Gainera, José $\mathrm{M}^{a}$ Etxebarria bera dugu grabaziook eta euren nondik norako guztiak sakonkien eta zehatzen aztertu dituen euskal ikerlaria. Gai honi buruz berak ondutako 11 artikuluetan ${ }^{5}$ hizkuntza-grabazio guztiak

3. TREBITSCH, Rudolf. 34. Mitteilung der Phonogramm Archivs-Kommission der kaiserl. Akademie der Wissenschaften in Wien. Baskische Sprach und Musikaufnahmen. Anzeiger der philosophisch-historischen klasse der kaiserlichen Akademie der Wissenschaften in Wien, Vol XI, Viena, 1914.

Euskaraturik: LOPEZ DE ARANA, Inaxio eta Marcelo. Rudolf Trebitsch: euskal hizkuntzaren eta musikaren grabazioak (1913). FLV (XXX. urtea, 77. zenbakia, 1998ko urtarrila-apirila), 97-117.

Gaztelaniaraturik: LOPEZ DE ARANA, Inaxio eta Marcelo. Rudolf Trebitsch: grabaciones de la lengua y la música vascas (1913), ETNIKER 11, 1999ko urria, 266-300.

4. Ikus ondoko bi lanak:

1 - Euskarazko lehen soinuak (CD-ROMa). Donostia: Eusko Ikaskuntza, 2000.

2 - LOPEZ DE ARANA, Inaxio. "Léon Azoulay: euskarazko lehen soinuak (1900)". EGAN, 2002 1/2, 5-40.

5. Hona José $M^{a}$ Etxebarriaren 11 artikuluok:

1 - "Vienako euskal grabaketak". EUSKERA XXIX, 1984-1, 395-397.

2 - "Las grabaciones en euskera de la fonoteca de Viena. Cuentos y anécdotas en dialecto vizcaino". Etniker - Bizkaia aldizkaria, 9. zk, 1990, 187-204.

3 - "Las grabaciones en euskera de la fonoteca de Viena. II. Grabaciones en dialecto labortano". Anuario de Euskal Folklore, 36. zk., 1990, 59 - 64.

4 - "1913ko Vienako euskal grabaketak, III. erronkariera". IKER-6, 161-176.

5 - "Euskalkietan egindako lehenengo grabaketak". IKER-7, 607-618.

6 - "Euskalki guztien etno-testuak". Eskola Apunteak 17, Labayru ikastegia, Bilbo, 1991, 26-33, 38-39, 96-

$104,138-140$.

7 - "Las grabaciones de Viena en euskera. Dialectos Alto navarro septentrional y meridional". Mundaiz 45, 1993, 19-28.

8 - "Las grabaciones de Viena en euskera. Bajo navarro occidental y Bajo navarro oriental". Mundaiz 47, 1994, 45-76.

9 - "Vienako euskal grabaketak. Bizkaiera". Enseiucarrean 11, 1995, 93-114.

10 - "Vienako euskal grabaketak. Zuberera". Enseiucarrean 12, 1996, 177-199.

11 - "Las grabaciones de Viena en euskera. Dialecto guipuzcoano". Mundaiz 46, 1993, 25-50. 
transkribaturik agertzen dira, bai eta zenbaitetan azterturik eta itzulirik ere. Gainera, oraindik orain liburu bat argitaratu du José $\mathrm{M}^{\mathrm{a}}$ Etxebarriak non sakonki aztertzen baititu 1913tik 1917ra bitarteko euskarazko hiru grabazio-bilduma, besteak beste, Trebitschena, jakina. Baina Trebitsch gurera etorri aurretik eta bateratsu zenbait euskal ikerlarik argitaratutako artikuluetan aipaturik agertzen da austriarraren egitasmoen berri $^{7}$.

Hizkuntza-grabazioek 130 minutu irauten dute denera; 64 diskotan banatuta daude eta bakoitzak bi minutu inguru irauten du. Euskalki guztietakoak daude, bai eta erronkarierakoak ere, euskalki hori dagoeneko desagertu bada ere. Denetariko testuak daude: ipuinak, kontakizunak, pasadizoak, abestiak... Abestien artean, "Agota" erromantzea osorik agertzen da eta Santa Agedaren omenezko kanta bat ere bai. Beti prozedura berbera erabiltzen zuten: lehenbizi, ipuina, abestia edo dena delakoa idazten zuten eta gero, grabatzeko tresnaren aurrean irakurri edo abesten zuten. Lanari gaina jartzeko, Trebitschen laguntzaileek gaztelaniara edo frantsesera aldatzen zuten testua, gero alemanera itzuli ahal izateko.

Hizkuntza-grabazioak, beraz, eskuratuta eta behar bezala ikertuta geneuzkan, baina zer gertatu ote zen grabazio musikalekin? Hutsune horri antzemanda, duela zenbait urte lanean hasi ginen euskal kulturaren harribitxi horiek Euskal Herrira ekarri eta gaia behar bezala argitu eta zabaltzeko. Akuilu horrek sustaturik eta hainbat lagunek emandako laguntzari esker, 2003ko urtarrilaren 13an eskuratu ahal izan genituen Rudolf Trebitschek 1913an egindako grabazio musikalak. Berlingo Fonograma Artxiboan zeuden ${ }^{8}$, eta Susanne Ziegler eta Albrecht Wiedmann doktoreekin hitzartutako itun bati esker erabili ahal izan genituen.

Grabazio musikalei "Trebitsch Basken" izena ezarri zieten Berlinen, eta 14 disko edo zilindrotan banatuta utzi zizkidaten, horietatik bi (2.208 eta 2.209 zenbakidunak) hizkuntzagrabazioen artean ere agertzen direlarik. Guztira, 32 minutu irauten dute, euskal kanta eta doinuz beteak. Grabatze-lanaren batez besteko abiadura minutuko 190 erreboluziokoa da, eta "Edison" motako zilindroak erabili zituzten grabazioetarako. Grabazio hauetan, Nafarroa

6. ETXEBARRIA, José Ma. Euskarazko grabaketak 1913-1917 Grabaciones en euskara. Erroteta argitaletxea. 2009.

7. Hona artikuluok:

1 - "El viaje del Doctor Trebitsch. Este investigador vienés recorre nuestro país enviado por la Academia Imperial de Ciencias de Viena". Julio Urkijo: Euskalerriaren Alde, 1913, III, 631-632.

2 - "Euskalerriaren Alde y el Archivo fonográfico y el Museo Etnológico de Viena. Cartas cruzadas con motivo del viaje de doctor Trebitsch al País Vasco". Gregorio Mugica: Euskalerriaren Alde, 1913, III, 682-683.

3 - "De lingüística y etnografías vascas. A propósito del viaje del Dr. Rodolfo Trebitsch". Julio Urkijo: RIEV, 1913, VII, 575-583.

4 - "Baskische Sprach- un Musikaufnahmen ausgefürht im Sommer, Wien, 1914". Gregorio Mugica: Euskalerriaren Alde, 1914, IV, 552.

8. Grabazio hauek jatorriz zilindro itxurako argizarizko euskarri batzuetan jasota zeuden, eta, Trebitschek egindako euskal hizkuntza-grabazioak bezala, Vienako Fonograma Artxiboan gordeta egon ziren hainbat urtez. Behinola, grabazio musikal haien kopia bat Berlinera bidali zuten, Berlingo Fonograma Artxibora hain zuzen. Urteak joan eta urteak etorri, Vienan zeuden jatorrizko zilindro edo grabazio haiek galdu omen ziren, eta pentsatzekoa da Berlingoa dugula jatorrizko zilindroen kopia bakarra. Guri kopia digitalizatua egin ziguten, CD batean bilduta; jatorrizko zilindroen kopia Berlinen geratu zen. 
Behera, Bizkaia, Gipuzkoa eta Zuberoako kantari eta musikariak ditugu entzungai, Donibane Garazi, Igorre, Azpeitia, Tolosa eta Atharratzekoak, hurrenez hurren. Haien izenak ere badakizkigu, Trebitschek utzitako dokumentazioari esker. Gainera, Austriako etnologoak zerrenda batean bildu zituen berak egindako euskal grabazio musikal guztiak. Zorionez, zerrenda hori Trebitschek utzitako dokumentazioan zegoen, eta artikulu honen bukaeran txertatu dugu. Bitxia da, bestalde, zerrenda horretan aipatzen direla Berlinen aurkitu ez genituen lau disko: 2.215, 2.236, 2.237 eta 2.244 zenbakia dutenak. Bilduma honetan ez egonagatik, erraz aurki ditzakegu José Ma Etxebarriak 1984an Vienatik ekarritako grabazioen artean. Izan ere, Rudolf Trebitschek 1913ko udan egindako euskal grabazio ia guztiak aurkitu ditugu azkenean. Ale bat falta da, ordea, 2.216 diskoa, Markinako Martin Barinaga hizlari duena. Idi-probez eta pilota-partida batez omen ziharduen grabazioan, baina, zoritxarrez, bidean galdu da. Beste guztia eskuratu dugu.

Grabazioetarako erabili ziren musika-tresnez bezainbatean, guzti-guztiak Vienara eraman zituen Trebitschek, hain zuzen ere Austriako Etnologia Museora. Gaur egun oraindik Vienan daude, baina Austriako Zientzietako Akademiaren Fonograma Artxiboan, duela zenbait urte hara aldatu zituztelako.

Euskal grabazio musikalei buruzko xehetasun guztiak aletzen hasi aurretik, nire eskerrik beroenak eman nahi dizkiet Eresbil artxiboko langileei, batez ere Jaione Landaberea eta Jon Baguesi, bai eta Herri Musikaren Txokoko Juan Mari Beltran Argiñenari ere, ondoren doazkizuen datuetarik asko eta asko haiek eman dizkidatelako. Nire esker ona merezi dute, orobat, Errenteriako Andra Mari abesbatzako zuzendari eta Eresbil artxiboko langile den José Manuel Tifek -berak sortu baititu grabazioen partiturak-, Jon Miner soinu-tenikariak eta Josu Sarasa partitura-digitalizatzaileak. Haien guztien laguntza funtsezkoa izan da lan hau hezurmamitzeko orduan.

\section{ZILINDROA:}

Laguntzailea: Georges Lacombe euskalaria.

Herria: Donibane Garazi (Nafarroa Beherea).

Lekukoa: Pierre Jenda nekazaria.

Gaia: irrintzia.

Iraupena: 1:40 min.

Oharrak: hona zer dioen Trebitschek zilindro honi buruz': «Eskuarki, artzainek mendi

9. Aipamen hau eta beste zilindroen oharretan agertzen direnak artikulu honetatik hartu eta euskaratu ditut: TREBITSCH, Rudolf. 34. Mitteilung der Phonogramm Archivs-Kommission der kaiserl. Akademie der Wissenschaften in Wien. Baskische Sprach und Musikaufnahmen. Anzeiger der philosophisch-historischen klasse der kaiserlichen Akademie der Wissenschaften in Wien, Vol XI, Viena, 1914. 
gailurretatik irrintzi egiten diote elkarri. Elkarrekin komunikatzeko halako seinale bat da. Batzuetan, lana behar bezala egindakoan egiten den agur-oihua besterik ez da; irrintziak Tiroleko kantuen antza du». José $\mathrm{M}^{a}$ Etxebarriak 1984an ekarritako 2.193. diskoan ere agertzen da irrintzi hau.

\section{ZILINDROA:}

Laguntzailea: Gabriel Rody margolaria.

Herria: Atharratze (Zuberoa).

Lekukoa: Bernhard Haritxelar arotza.

\section{Doinuak:}

1- «Ostalersa»: txirula eta tuntuna (47 seg.).

2- «Lili ederra» («Lili eder bat» delakoaren bertsio bat): txirula eta tuntuna (35 seg.).

3- «Satan-dantza» (Zuberoako pastoraletakoa): txirula (19 seg.).

4- «Turkoen airea» (Zuberoako pastoralen hasierako martxa): txirula (23 seg.).

Iraupena (guztira): 2:12 min.

Oharrak: Trebitschen hitzak:

-1. doinuari buruz: «Emakume ostalari baten kanta da; dantzatzeko da. Kontakizunaren edukia hauxe da gutxi gorabehera: tabernari batek bost eta sei zentimoko ardoa dauka. Bezero batek zerbait ekartzeko agintzen dio».

-2. doinuari buruz: «Amodiozko kanta da; bertan kantariak loreei galdetzen die ea maite ote duten».

-3. doinuari buruz: «Dantzatzeko kanta da. Mozorro-jaietako deabruek son horretan dantzatzen dute. Doinua "Bon voyage, Mr Dumollet" izeneko kantatik hartutakoa da, baina pitin bat desberdina da konpasari dagokionean».

-4. doinuari buruz: «Doinua artzainen aspaldiko kanta batetik dator. Ehundaka urte bide ditu».

\section{ZILINDROA:}

Laguntzailea: Gabriel Rody margolaria. 
Herria: Atharratze (Zuberoa).

Lekukoa: Bernhard Haritxelar arotza.

Doinuak:

1 - «Pello Joxepe»: txirula (minutu bat, 6 seg.).

2 - «Fandangoa»: txirula (17 seg.).

3 - «Kauter dantza» (Zuberoako maskaradakoa): txirula (27 seg.).

Iraupena (guztira): 2:11 min.

Oharrak: Trebitschen hitzak: «Kanta satirikoa da. Zenbait lagunek batera abesteko da".

\section{ZILINDROA:}

Laguntzailea: Gabriel Rody margolaria.

Herria: Atharratze (Zuberoa)

Lekukoa: Bernhard Haritxelar arotza.

Doinuak:

1- «Marche de cavalcade de la Basse Navarre» (Luzaideko Bolantietan edo Luzaideko Dantzan ere erabiltzen dute): txirula eta tuntuna (minutu bat, 25 seg.).

2- «Barikala» («Satan-dantza», eta Luzaideko Bolantietan «Andre-dantza» izena ematen diote): txirula eta tuntuna (25 seg.).

3- «Valse italienne» (osatu gabe dago, fandangoaren erritmoa du, eta egitura «Pipa hartuta» abestiaren antzekoa du): txirula eta tuntuna (15 seg.).

Iraupena (guztira): 2:19 min.

Oharrak: hona zer dioen Trebitschek 1. doinuari buruz: «Ezezagun batek sortu zuen kanta hura, martxetan erabiltzeko».

\section{ZILINDROAREN 2. BERTSIOA.}

Berdin-berdina da, pixkat laburragoa baina: 2 minutu eta 14 segundo irauten du guztira. 


\section{ZILINDROA:}

Laguntzailea: Julio Urkijo idazlea.

Herria: Igorre (Bizkaia)

\section{Lekukoak:}

1- Anbrosio Gorostiaga morroia (Igorre, 1867 - Igorre, 1926), alboka, 46 urtekoa. Aita eta aitonarengadik datorkio alboka jotzeko zaletasuna.

2- Josefa Ealo neskamea, panderoa (ez da entzuten), 30 urtekoa, Bediakoa.

\section{Doinua:}

- «Artolak deuko» herri-kanta.

Iraupena: 2:16 min.

\section{ZILINDROAREN 2. BERTSIOA.}

Berdin-berdina da, pixkat laburragoa baina: bi minutu eta 9 segundo irauten du guztira.

\section{ZILINDROA:}

Laguntzailea: Julio Urkijo idazlea.

Herria: Igorre (Bizkaia)

Lekukoak: 5. zilindroko musikari berak: Josefa Ealo, ahotsa eta panderoa; Anbrosio Gorostiaga, alboka.

\section{Doinua:}

- «Asiko nas asitzera»: incipit literarioa da, hau da, "Asikonaz asitzera" kantaren lehenengo hitzak. Fandangoaren erritmoa du. Hau ez da Azkueren kantutegian bildurik dagoen kanta.

Honela dio ${ }^{10}$ :

Asiko nas asitzera

Onelan berdintzera

Ni onelan ikusite

10. Trebitschen dokumentazioan dagoen bezala transkribatu dut. 


\author{
Alegretuten etzara? \\ Neure laztana non sera? \\ Inon agiri etzera \\ Beste guztiek ezkondute \\ Zeu bakarrik lotu sera \\ I neskatille morenea \\ Marrenesko gonea \\ Abaska kordet baltzakas \\ Dirudi probentziania \\ I neskatillatsu larrosa \\ Zeure berbea donosa \\ Sarriten eukiten dot nik \\ Zeu ikusi poza.
}

Iraupena: 2:08 min.

\title{
7. ZILINDROA:
}

Laguntzailea: Julio Urkijo idazlea.

Herria: Igorre (Bizkaia)

Lekukoak: 5. eta 6. zilindroetako musikari berak: Josefa Ealo, ahotsa eta panderoa; Anbrosio Gorostiaga, alboka.

Doinua:

- «Adios Atxuri te»: incipit literarioa. Porrusaldaren edo arin-arinaren erritmoa du.

Honela dio ${ }^{11}$ :

Adios Atxuri te adios banoa

Bier etorriko nas urrin ezpanoa

Adios aiteri te adios amari

Orain banoiela Zaragozara ni

Goirengo kaniarada lidea labana

Galdara sorzutata mutil barrabana

Txikitxu polit hori, norena, norena,

Aitena da amena, Jangoikorena.

Iraupena: 2:05 min.

11. Trebitschen dokumentazioan dagoen bezala transkribatu dut. 
Oharrak: Trebitschen hitzak: «Zazpigarren zilindroan dago seigarren zilindrokoaren amaiera: abestian kantariak neska mairu bat irrikatzen duela dio. Kantariak haren edertasuna goresten du. Orobat, neska hark lokarri beltzekiko abarkak dauzkala azpimarratzen du, altuera txikiko oinetako tradizionalak, alegia. Abarken ezaugarri horiek kontuan izanda, berak uste du neska hura Gipuzkoakoa dela. Zazpigarren zilindroaren bigarren zatian kanta bat dago eta bertan Atxuriko mutil bat agertzen da eta Zaragozara doanez, bere gurasoei agur egiten die. Nire iruzkingileak esan didanez, bertan kontatzen da nola eramaten duten mutil hura, arazo psikologikoak baititu, Zaragozako eroetxera».

Kanta honek badu tarte hau Trebitschek bere dokumentazioan idatzi zuen bezala kopiatuagatik, antzik hartzerik ez dagoena: «Goirengo kaniarada lidea labana/Galdara sorzutata mutil barrabana».

\section{ZILINDROA:}

Laguntzailea: Gregorio Mujika ingeniari eta idazlea.

Herria: Azpeitia (Gipuzkoa).

Lekukoak:

1. Sebastian Errasti mekanikaria, 28 urtekoa, dultzaina.

2. Gregorio Larralde igeltsero-burua, 57 urtekoa, danborra.

Doinuak:

1 - «Eztaitarra» (200 urte inguru dituen eztei-martxa): danborra eta dultzaina (minutu bat, 1 seg.).

2 - «Andre Maddalen» («Madalen busturingo»): danborra eta dultzaina (23 seg.).

3 - «Kontsesiri» (gaur egun doinu hori ezaguna da izenburu hauekin: «Txantxibiri txantxibiri gabiltzanian», «Atxiketan-potxiketan» edo «Zantziki, zantzikitin». Letran aldaketak daude, baina funtsean doinu bera da): danborra eta dultzaina (35 seg.).

Iraupena (guztira): 2:15 min.

Oharrak: hona zer dioen Trebitschek 2. doinuari buruz: «Euskal fandangoari egokitutako doinu bat, dantzatzeko dena. Doinu horri lotutako letraren edukia hauxe da, gutxi gorabehera: gizon batek emakume bati olioa erosi ondoren esaten dio bere aitak soldata jasotzen duen bitartean ordainduko diola». 
98

\section{ZILINDROA:}

Laguntzailea: Gregorio Mujika ingeniari eta idazlea.

Herria: Azpeitia (Gipuzkoa).

Lekukoak:

1. Sebastian Errasti, dultzaina.

2. José María Gurrutxaga errementaria, 32 urtekoa, dultzaina.

3. Gregorio Larralde, danborra.

Doinuak:

- «Baserritarra» (fandango-erritmoa du): bi dultzaina eta danbor bat (minutu bat, 12 seg.).

- Porrusalda («arin-arina»): bi dultzaina eta danbor bat (54 seg.).

Iraupena (guztira): 2:13 min.

Oharrak: Trebitschek dioenez, arin-arina oso zaharra da.

\section{ZILINDROA:}

Laguntzailea: Baleriano Mokoroa.

Herria: Tolosa (Gipuzkoa).

\section{Lekukoak:}

1. Leandro Zabala, 34 urtekoa. Musika-tresna hauek jotzen ditu: lehenengo txistua, tuntuna eta palilloa (euskal "txotxa").

2. Alberto Alberdi, 19 urtekoa. Musika-tresna hauek jotzen ditu: txistua, tuntuna eta palilloa.

3. José Txintxilla, 34 urtekoa. Tolosako musika-bandan jo zuen. Silbotea.

4. Baleriano Mokoroa bera. Atabala.

Doinua: "Vals con variaciones", Bilboko orkestra-zuzendari Federico Cortorena. Doinuak fandango-erritmoa badu ere, motelagoa da, baltsea bezalakoa. Oso ezaguna da.

Iraupena: 2:18 min. 
Oharrak: Trebitschek dioenez, musikari-laukote honi udalak ordaintzen zion jaietan plazaz plaza jotzen ibil zedin.

\section{ZILINDROA:}

Laguntzailea: Baleriano Mokoroa inprimatzaile eta idazlea.

Herria: Tolosa (Gipuzkoa).

Lekukoak: 10. zilindroko berberak dira, alegia: Leandro Zabala, Alberto Alberdi, José Txintxilla eta Baleriano Mokoroa.

Doinua: "San Juan Zortzikoa" kanta.

Kantak honela dio ${ }^{12}$ :

Agur egun zoragarriya

poztu dezu erri guztiya.

Ilunabarreko danbolinak

ta elizako ezkilak

sendatu dituzte gaixorik zeuden

neska koskor eta mutilak.

Agur egun zoragarriya

poztu dezu erri guztiya.

Albo herritik jendea

onratzera S. Juan gurea

eta zail dalako nunnahi arkitzen

dute leku bat hobea

Agur egun zoragarriya

poztu dezu erri guztiya.

Patroi gurearen ikasbidea

beti dezagun goguan

noizbait kantatzen gerta zaitezen

danok beraren onduan.

12. Trebitschen dokumentazioan dagoen bezala transkribatu dut. 
Agur egun zoragarriya

poztu dezu erri guztiya.

Iraupena: 2:10 min.

Oharrak: Trebitschen hitzak: «San Juan Tolosako patroia da. Han 5/8 konpasa erabiltzen da, hots, euskal musikaren berezko konpasa. Martxa horren bidez goresten dira santuaren eginak, San Juan egunean zenbait ahapalditan kantatzen baitziren».

\section{ZILINDROA:}

Laguntzailea: Baleriano Mokoroa.

Herria: Tolosa (Gipuzkoa).

Lekukoa: Demetrio Oiarzabal botikaria.

Doinua: «Gernikako arbola». Musika-tresnarik ez, kantua bakarrik.

Kantak honela dio ${ }^{13}$ :

Gernikako arbola

Da bedeinkatuba

Euskaldunen artian

Guztiz maitatua.

Gernikako arbola

Da bedeinkatuba

Euskaldunen artian

Guztiz maitatua.

Eman da zabaltzazu

Munduan frutua

Adoratzen zaitugu

Arbola santua.

Eman da zabaltzazu

Munduan frutua

Adoratzen zaitugu

Arbola santua.

13. Trebitschen dokumentazioan dagoen bezala transkribatu dut. 
Iraupena: 1:46 min.

Oharrak: Trebitschen hitzak: «Gernikako arbola hau duela ehunka urte landatu zen Gernikan, Espainiako Euskal Herrian, eta esan liteke zuhaitz hori euskaldunen independentziaren ikurretako bat dela. Zilindro honetan ereserki nazionalaren bi ahapaldi entzun ditzakegu. Kantan arbola bedeinkatzen da eta bere fruituak goresten dira. Letra eta musika Iparragirre izeneko batek sortu zituen. Berriro ere 5/8 konpasarekin egiten dugu topo, alegia, benetako euskal konpasarekin».

\subsection{DISKOA}

Laguntzailea: Gabriel Roby margolaria.

Herria: Atharratze (Zuberoa)

Lekukoa: Bernhard Haritxelar arotza, txirula eta tuntuna.

Doinua: «Monein» dantza (Biarnon jatorria duen euskal jauzia).

Iraupena: 1:36 min.

Oharrak: Trebitschen hitzak: «Doinu hau dantza baten akonpainamendua da. Tradizioaren arabera, dantza hori gizonek egiten dute, ez beste inork. Txistuak doinua markatzen du eta tuntunak akonpainamendua». Disko hau José $\mathrm{M}^{a}$ Etxebarriak 1984an ekarritako grabazioen artean ere badago.

\subsection{DISKOA}

Laguntzailea: Gabriel Roby margolaria.

Herria: Atharratze (Zuberoa).

Lekukoa: Bernhard Haritxelar arotza, txirula eta tuntuna.

Doinua: «Monein» dantza (hau ere Biarnon jatorria duen euskal jauzia).

Iraupena: 1:41 min.

Oharrak: 2.208. zilindroaz esandakoak balio du honetarako ere. Disko hau ere José $\mathrm{M}^{\mathrm{a}}$ Etxebarriak 1984an ekarritako grabazioen artean dago. 


\section{DULTZAINEROEN ZERRENDA}

Berlinen aurkitutako lekukotasun soinudun hauek ditugunez dultzainaren hots-grabazio zaharrenak, eta Juan Mari Beltran Herri Musikaren Txokoko zuzendariak gai honi buruz eman dizkidan argibideez baliaturik, «Trebitsch Basken» izeneko bilduma honetan agertzen diren dultzainero batzuei aparteko arreta eskaini nahi izan diet, haiei buruz xehetasun gehiago emanez:

\section{$\underline{\text { Azpeitia }}$}

Hiru dultzainero-danborrero:

\section{Sebastian Errasti "Xaxurra"}

Izatez Urrestillakoa zen, Trebitschek Azpeitikoa dela esan arren. Mekanikaria izan zen. «Urrestilla» izeneko atalean dituzue gizon honi buruzko datu gehiago.

\section{Gregorio Larralde}

1913an 57 urte zituen. Beraz, 1856an jaio zen. Danborra jotzen zuen. Igeltsero-burua izan zen.

\section{Jose Maria Gurrutxaga}

$1913 a n 32$ urte zituen. Beraz, 1881ean jaio zen. Errementaria izan zen.

\section{$\underline{\text { Urrestilla }}$}

\section{Sebastian Errasti «Xaxurra»}

Urrestillako "Atzan" baserrian jaio zen, 1892an (Rudolf Trebitschen dokumentuzioa ${ }^{14}$ kontuan hartzen badugu, 1885an jaio zen). Bere anaia Juan Inaziorekin jotzen zuen, biek duo eginez, eta «Eizmendi» baserriko Julianek danborrarekin laguntzen zien. Geroago, Jabier Goenaga "Arbe"rengana jo zuen eta honekin urte askoan aritu zen jotzen. Jabier Goenagaren seme Inaxio ala Bixente edo beste danborreroren batekin bat eginda, «Arbe»-«Xaxurra» dultzaina-talde honek herri eta festa askotan jotzen zuen, besteak beste Tolosako San Joanetan, Amezketan, Legorretan, Azpeitiko festetan, Nuarben, Matxinbentan, Urrestilako festetan, Urrestillako Santa Agedako eskean eta abarretan, eta horrelaxeko taldea osatuz agertzen dira argazki zahar askotan.

14.Datu hau eta beste hainbat artikulu honetatik hartu ditut: TREBITSCH, Rudolf. 34. Mitteilung der Phonogramm Archivs-Kommission der kaiserl. Akademie der Wissenschaften in Wien. Baskische Sprach und Musikaufnahmen. Anzeiger der philosophisch-historischen klasse der kaiserlichen Akademie der Wissenschaften in Wien, Vol XI, Viena, 1914. 


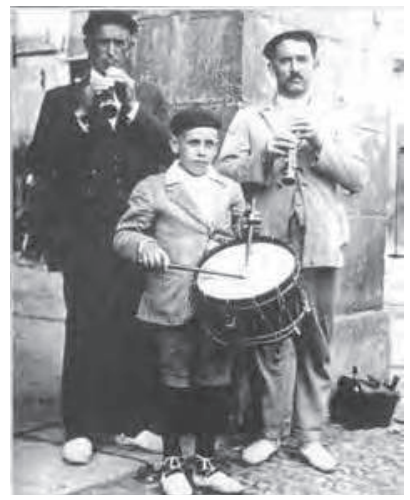

Jabier Goenaga "Arbe", Sebastián Errasti "Xaxurra" eta Inaxio Goenaga danborreroa (arg. H.M.)

Sebastian "Xaxurra" batzuetan metalezko dultzainarekin ikus dezakegu, besteetan zurezkoarekin eta giltzazko dultzainarekin ere bai. Jose Sudupe "Montte"k esanda, bagenekien "Xaxurra"k giltzazko dultzainarekin jo izan zuela eta horrela agertzen zaigu ondorengo argazkian.

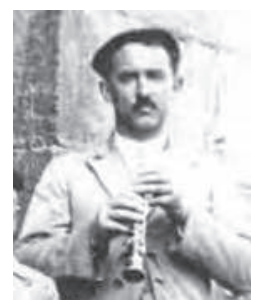

Sebastian Errasti «Xaxurra» (arg. H.M.)

Dultzaina hau bere alaba den Maria Guadalupe Errastik gordetzen du. Oso tresna bitxia da, Parisen egina, eta hauxe dauka grabaturik kanpai aldean: "Prosper Colas / Paris". Letoizkoa da eta eskala kromatiko osoa eman ahal izateko, bost giltza ditu, tutuaren letoiari erantsita, giltzazko sistematako beste soinu-tresnen modura.

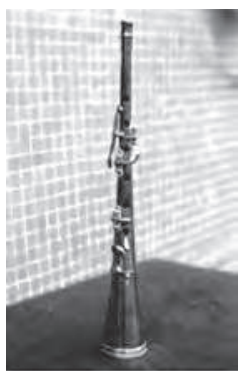

«Xaxurra»ren dultzaina, giltzazko letoizkoa (arg. jmba) 
Sebastian Errasti «Xaxurra»k musika idatzia ezagutu eta erabiltzen zuen, eta dultzainaz gain, beste soinu-tresna batzuk jotzen zituen, esate baterako, pianoa, eta musika bandan klarinetea eta tuba. Esaten dutenez, dultzainero honek dultzainak egiten zituen.

\section{TOLOSAKO TXISTULARIAK}

Lau dira Trebitschen grabazio musikaletan parte hartu zuten Tolosako musikariak: Leandro Zabala, Alberto Alberdi, José Txintxilla eta Baleriano Mokoroa. Txistulari horiek oso ezagunak izan ziren Gipuzkoan, XX. mendearen hasierako urteetan. Hori dela eta, azterlan honetan aipamen berezia merezi zutela iruditu zait. Txistulari haien nondik norakoen berri izateko, ezinbestekoak izan dira Juanmari Urruzola txistulari tolosarrak emandako argibideak eta utzitako argazkiak.

XX. mendearen hasieran, Leandro Zabalak, Alberto Alberdik, José Txintxillak eta Baleriano Mokoroak txistulari-talde bat osatzen zuten. Talde hura udal-taldea balitz bezala.

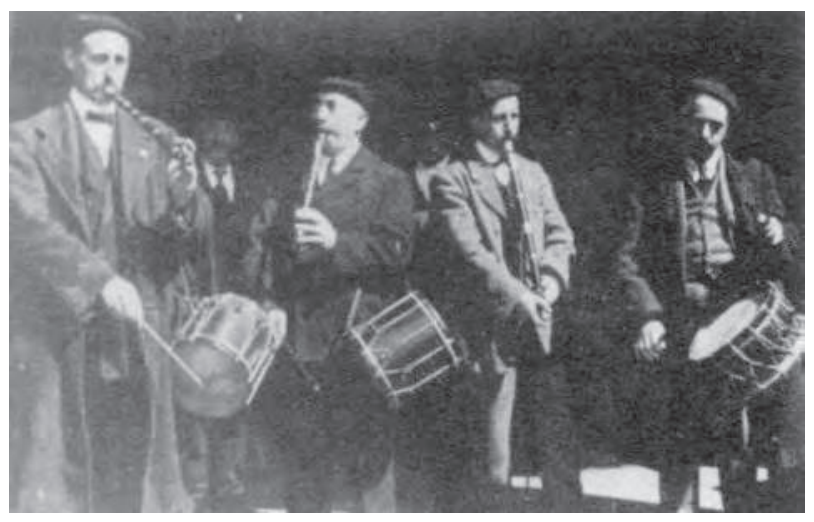

Ezkerretik eskuinera: Leandro Zabala, Blas Alberdi, José Txintxilla eta Baleriano Mokoroa (arg: "Txistulari" aldizkaria, 154. alea).

Udalarekin zeukaten kontratuaren arabera, gutxienez honako egun hauetan jo behar izaten zuten:

- Igande goizetan, zortzikoa, ohiko kaleetan barrena.

- Igande eta jaiegunetan, dantzarako musika.

- Udalbatza eratzeko ekitaldietan.

- Prozesioetan.

- Oro har, edozein ekitaldi ofizialetan. 


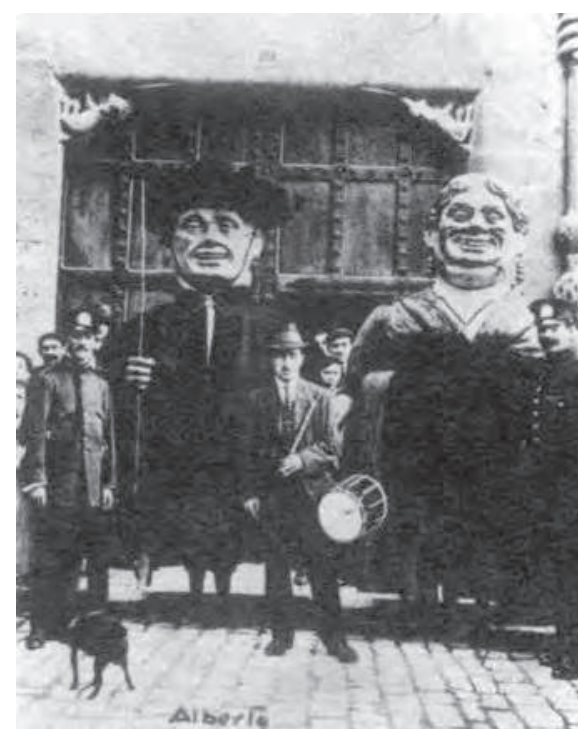

Alberto Alberdi, Burgos, 1916 (arg: "Txistulari” aldizkaria, 154. alea).

Gainera, beste herri batzuetan bezala, Tolosan ere taldeko zuzendariak hainbat doinu konposatu behar izaten zituen Udalerako. Tolosaren kasuan, urtean 12 pieza izaten ziren. Neurri handi batean, horri eskerrak ez ditugu galdu aspaldiko txistulari askoren obrak, esaterako, Leandro Zabalarenak.

Dirudienez, Zabalak, Alberdik, Txintxillak eta Mokoroak osatutako taldeak maila dezente ona izan zuen. Inguruko herrietan ibili ziren, bai eta Euskal Herritik kanpo ere. Gainera, "Fiestas Euskaras" zirela-eta antolatzen ziren txistu-talde txapelketa batzuetan irabazi zuten, hala nola 1908an Eibarkoan, 1909an Hernanikoan eta 1910ean Azkoitikoan.

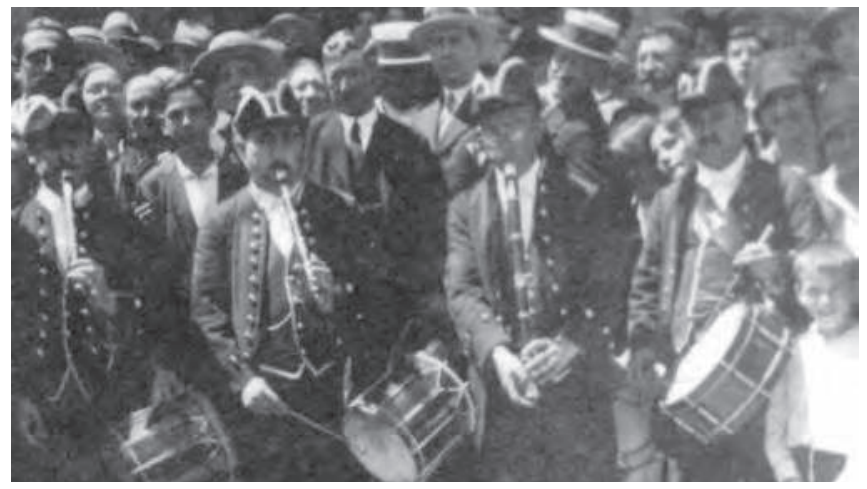

Ezkerretik eskuinera: Miguel Martinez de Lezea, Alberto Alberdi, José Txintxilla eta Esteban Iribas, A Coruña, 1925 (arg: "Txistulari" aldizkaria, 154. alea). 
Leandro Zabala txistularia ez ezik, txistu-irakaslea ere izan zen; Isidro Ansorenari eskolak eman zizkion. Trebitsch gurera etorri zen urtean -1913an- utzi zuen txistulari-taldea. Miguel Martinez de Lezeak bete zuen haren lekua, eta han jarraitu zuen 1970 arte.

Baleriano Mokoroa, besteak beste, inprimatzailea eta idazlea izan zen, bai eta "Ibaizabal" euskara hutsezko aldizkariaren Tolosako arduraduna ere. Justo $\mathrm{M}^{\mathrm{a}}$ Mokoroa "Ortik eta Emendik" esaera-bildumaren egilearen aita ere izan zen.

Garai hartan eta gaur egun arte hauxe izan da Tolosako txistulari-taldearen osaera: txistu lehena eta zuzendaria (beraz, txistua eta danbolina jotzen ditu); txistu bigarrena (honek ere txistua eta danbolina jotzen ditu); silbotea; eta atabala.

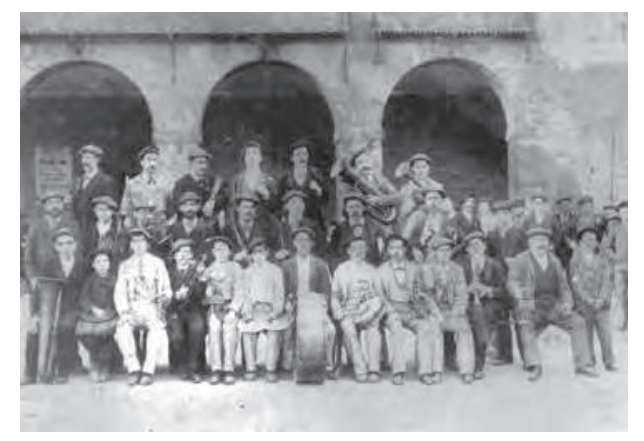

Tolosako musika-banda Foruen Plazan XIX. mendearen bukaeran. José Txintxilla dugu goiko lerroko bigarrena, ezkerretik hasita (arg: «Argazkiak Tolosa - Fotografías (1842-1900)». José María Tuduri Esnal. Kutxa. 1992).

Aspaldi bere eginkizunetarako zeukan talde hari, 1916an, izen ofiziala eman zion Udalak: "Banda Municipal de Txistularis". Udal-banda hartan sartu ziren ordura arte Udalarekin harreman estua zuen baina Udalarena ez zen txistulari-talde hartako bi kide gutxienez: Alberto Alberdi eta José Txintxilla. Izan ere, Alberto Alberdik bere aita Blasek utzitako lekua bete zuen 1913an.

\section{PARTITURAK}

\section{ZILINDROA:}

- «Ostalersa» (47 seg.): 


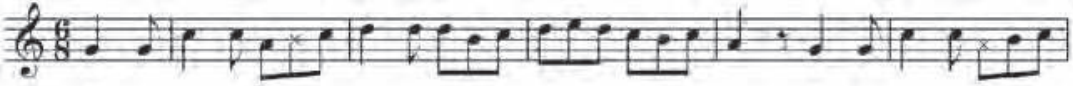

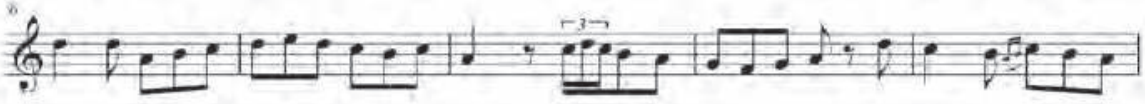

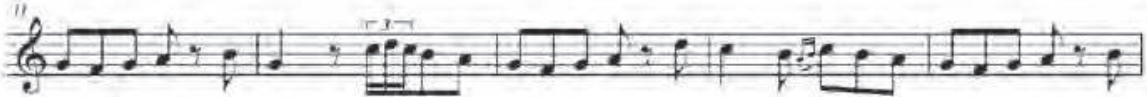
b. .... (2)

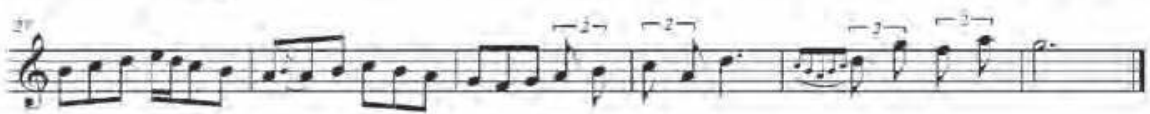
- «Lili ederra» (35 seg.):

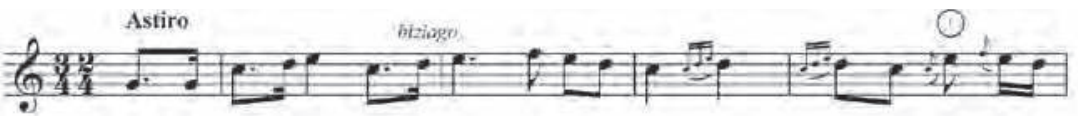

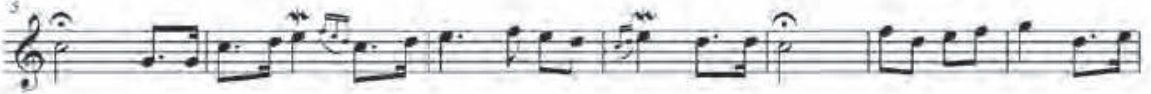

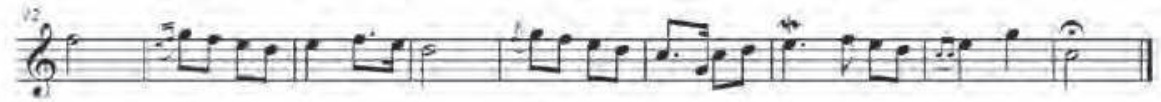

Q Geldencisathi het

- «Satan-dantza» (19 seg.):

68

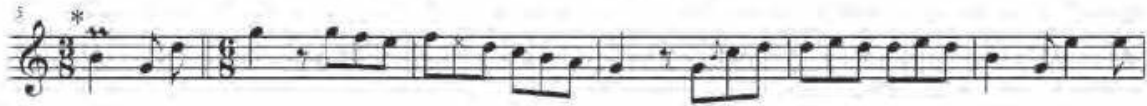
bํ..… ‥

* Irregulartasuna: kortxer bat erantsi zaio pultso honi (akkats teknikon ote?) 
- «Turkoen airea» (23 seg.):

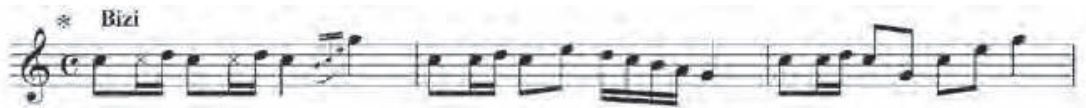

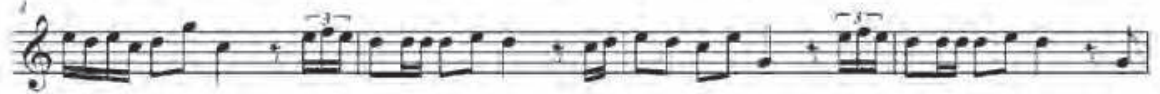

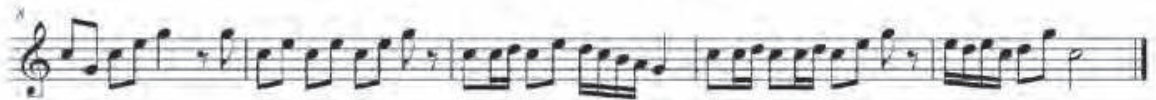
* Do soimua altu entzuten des

\section{ZILINDROA:}

- «Pello Joxepe» (1 min., 6 seg.):
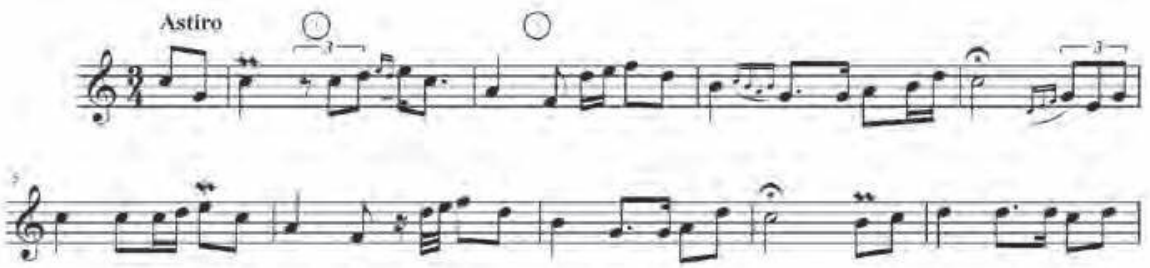

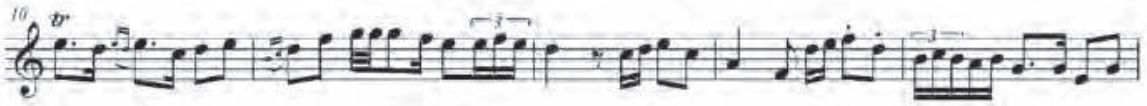

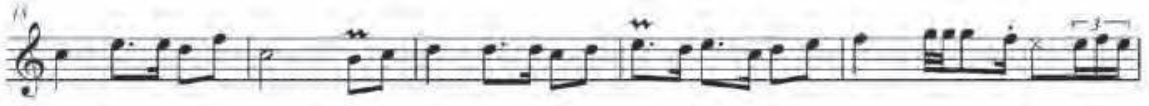

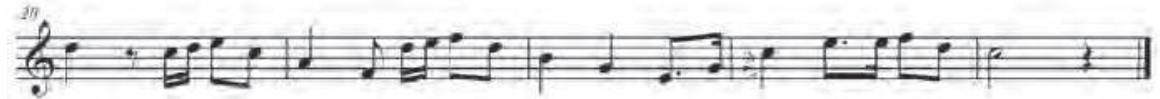
(1) octsimetinitut

- «Fandangoa»: txirula (17 seg.):

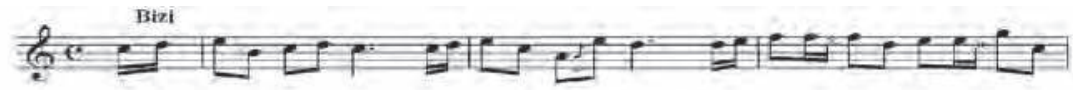

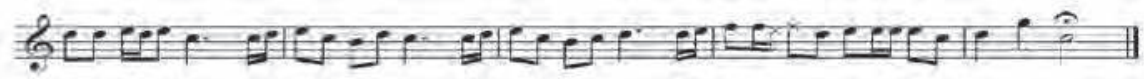


- «Kauter dantza» (27 seg.):
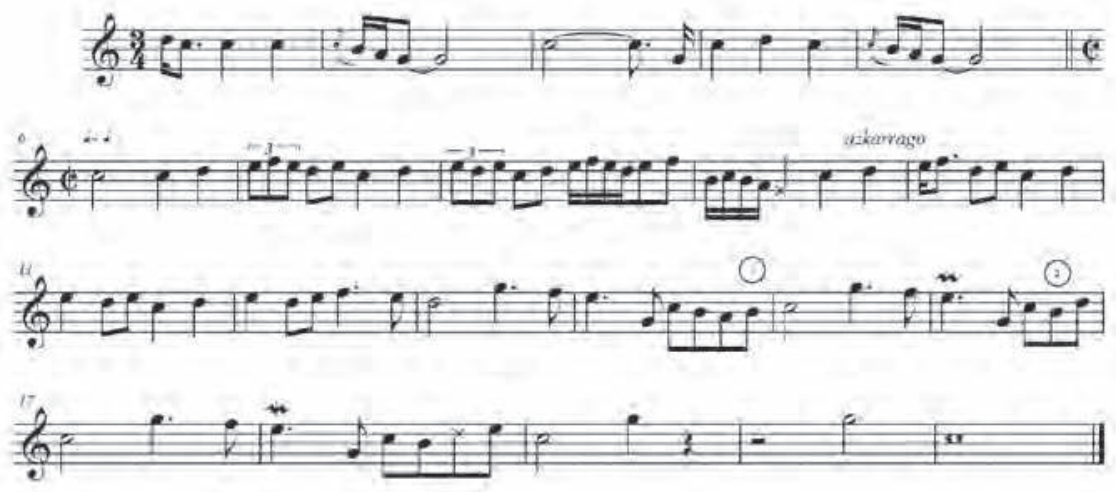
(1) Geldiene isiki bat
Rorreat bor falla dis 


\section{ZILINDROA:}

- «Marche de cavalcade de la Basse Navarre» (1 min., 25 seg.):

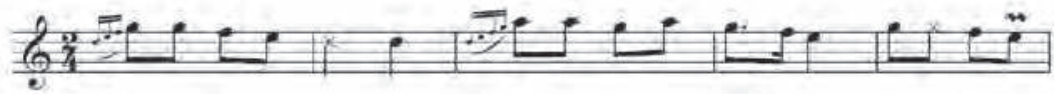

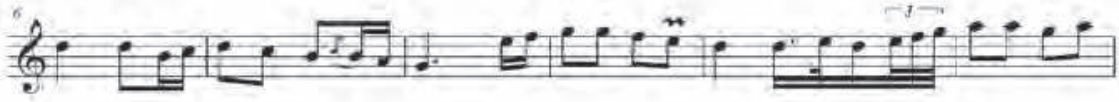 to. tof

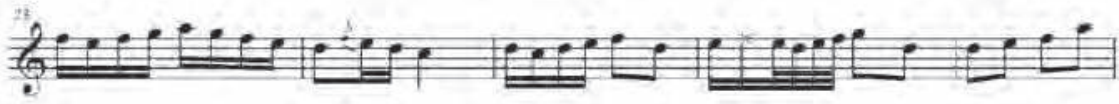 town

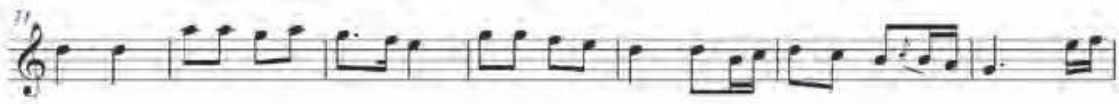

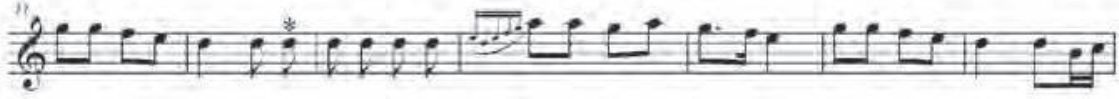 bु.

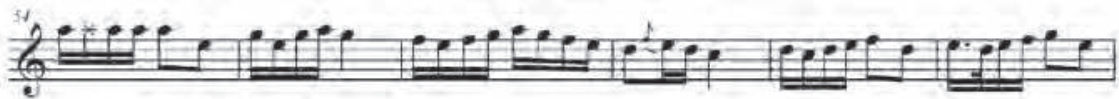 bon}


- «Barikala» (25 seg.):
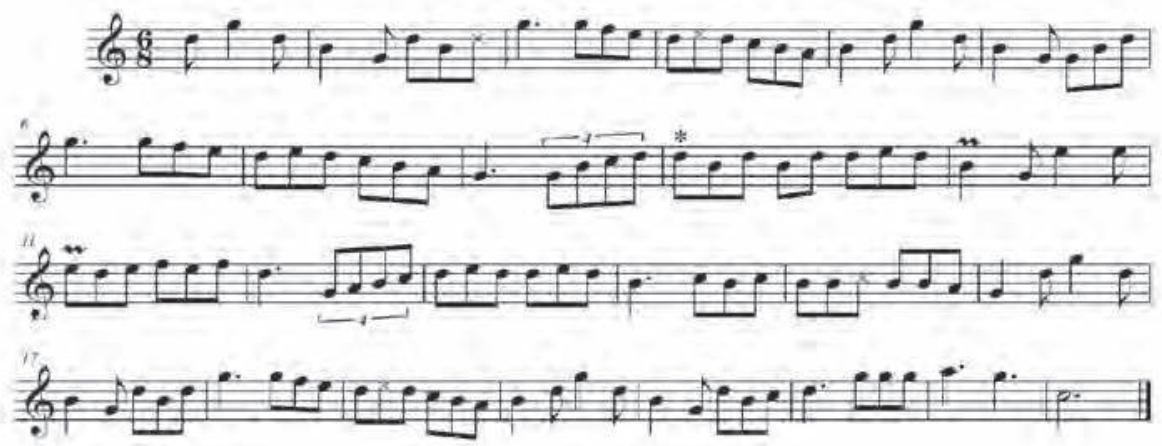

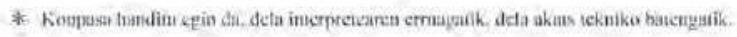

- «Valse italienne» (15 seg.):
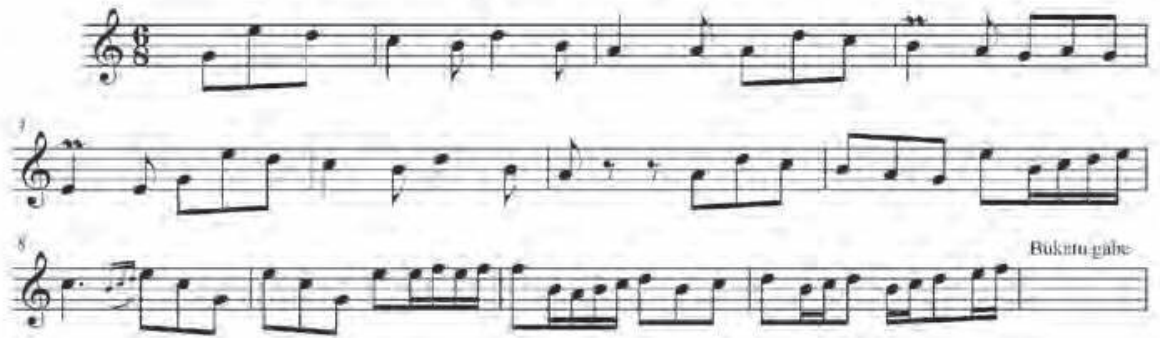
112

4. ZILINDROA (bigarren saialdia):

1 Bi desberdinasun daude:

a)ts.

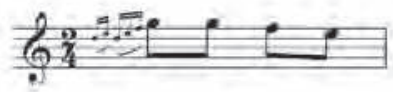

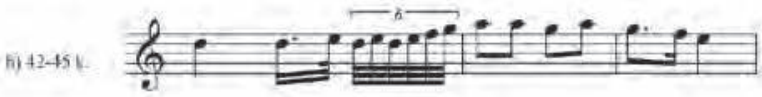

2. Desherdintasun bat dago:

sig. $k$.

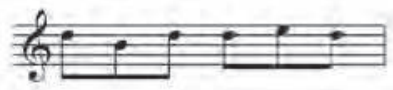

[7] Exdago desbcrdimasunik: 
5. ZILINDROA:

- «Artolak deuko» (2 min., 3 seg.):

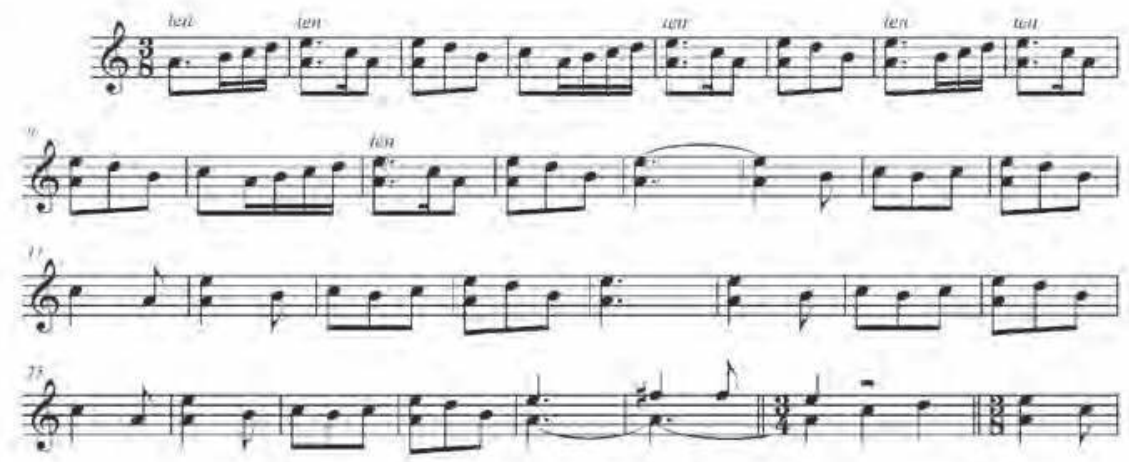

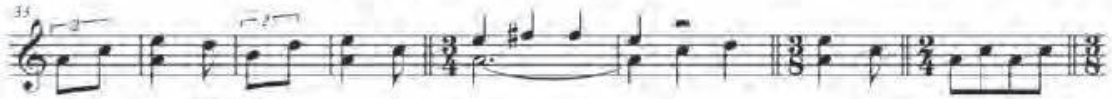

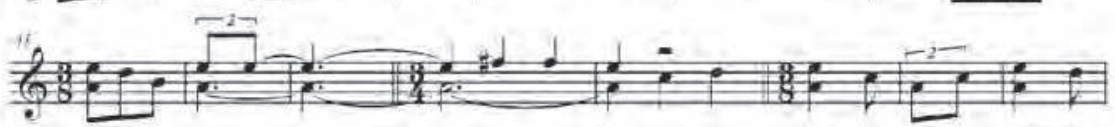

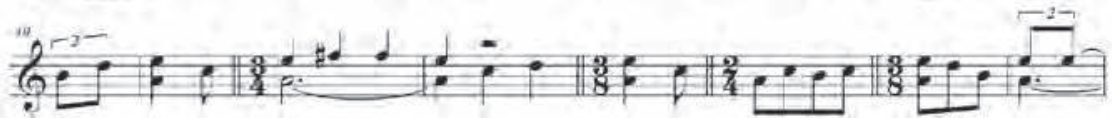

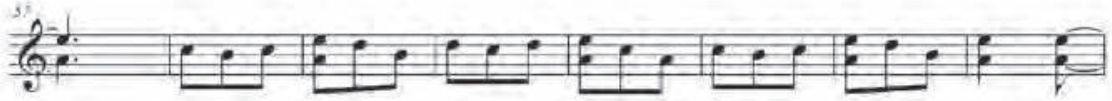
to: La:-:

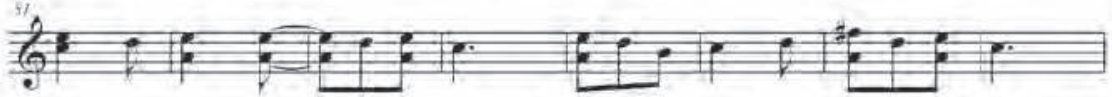
+9. 


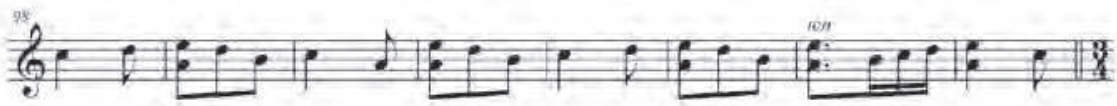

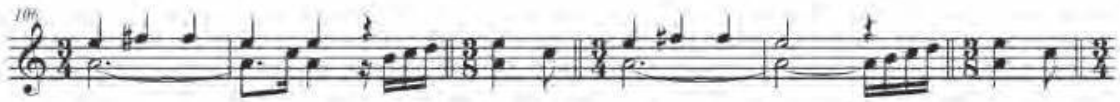

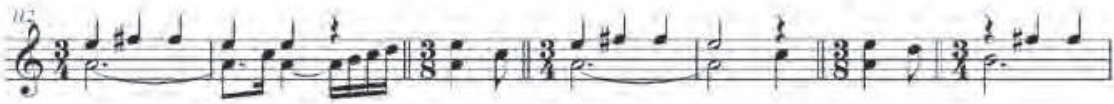
6. tat

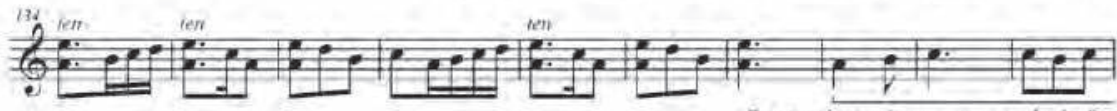

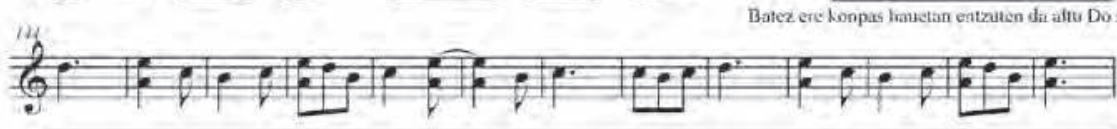

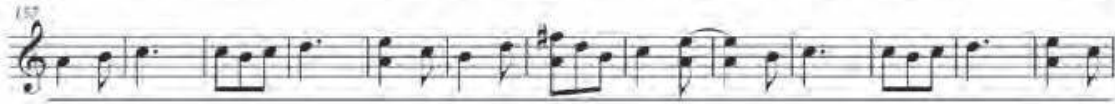
6ै

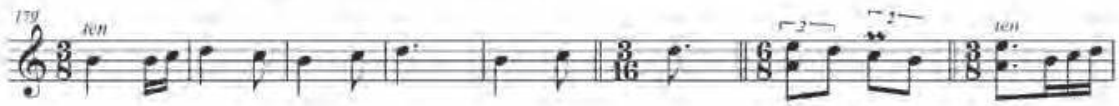
b: हn:

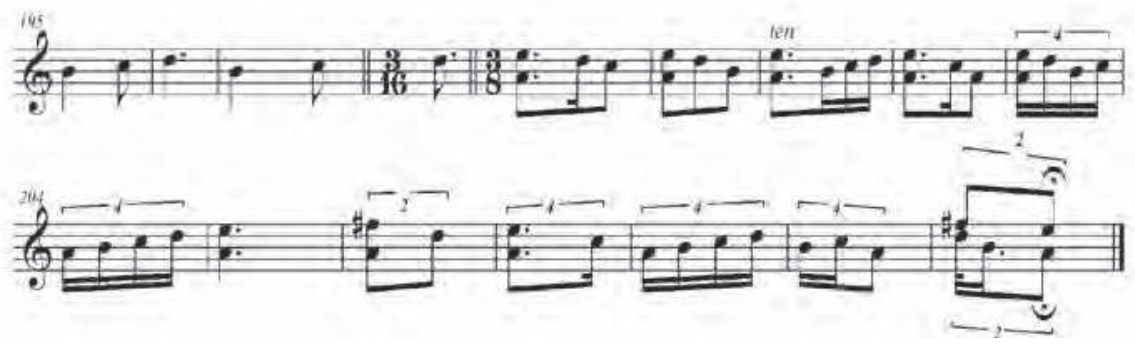




\section{ZILINDROA (bigarren saialdia):}

Erreprodukzio-abiadura lehenengo saialdikoa baino handiagoa da, doinua azkarragoa delako eta tonu erdi bat altuago entzuten delako. Ez dago desberdintasun gehiagorik.

\section{ZILINDROA:}

- «Asikonas asitzera» (2 min., 4 seg.):
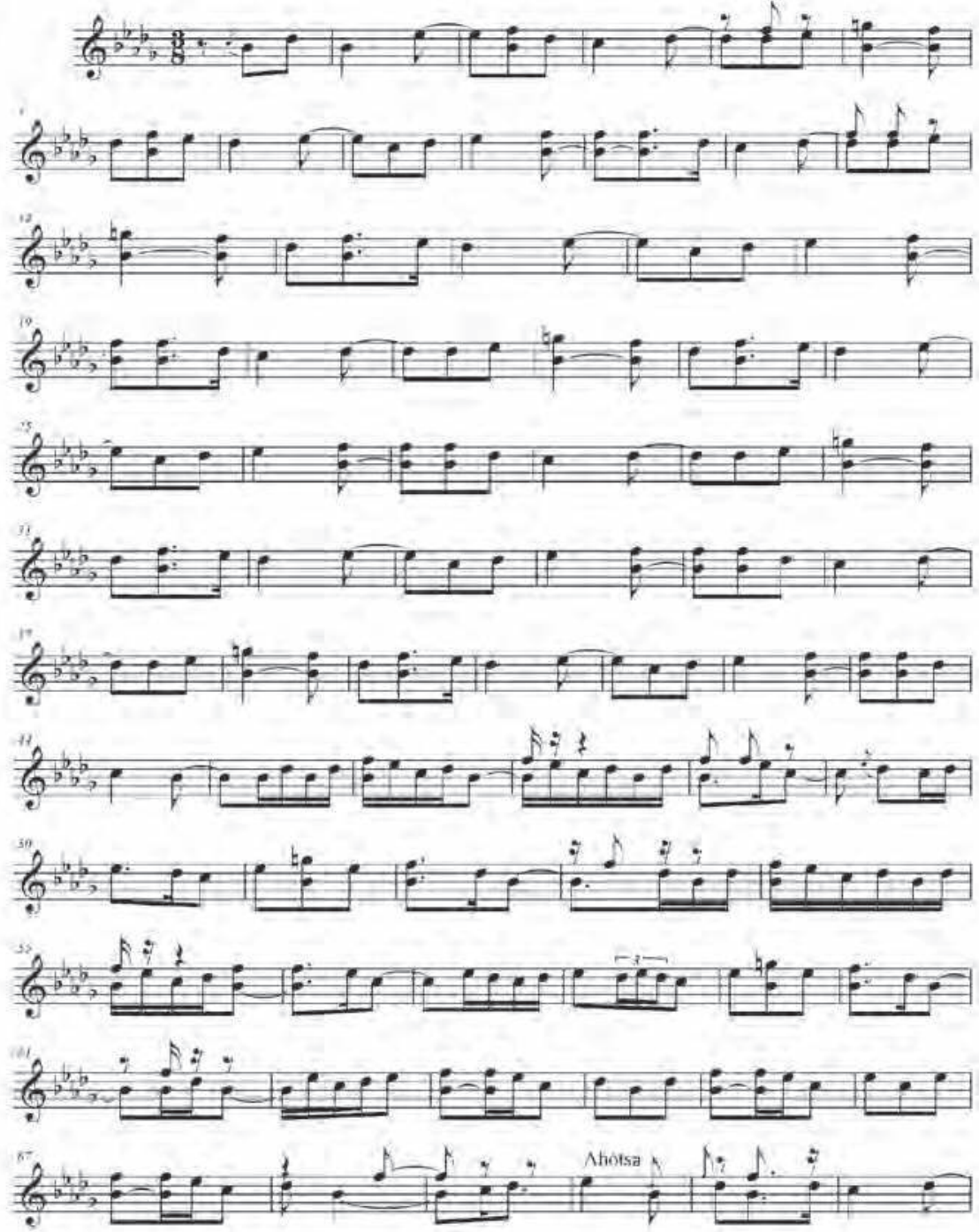
6) :

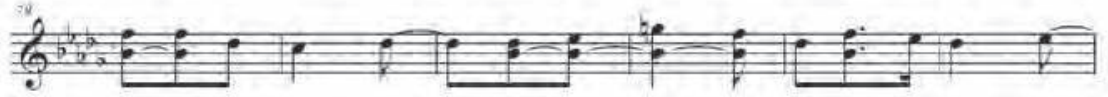
to: : : : : : : : : f?: : : : : : : :

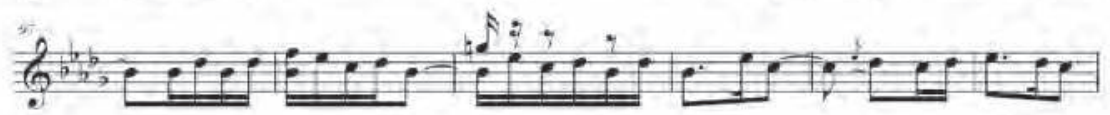

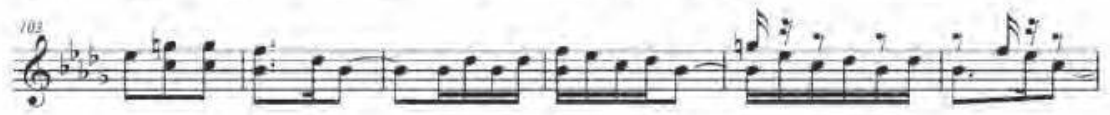

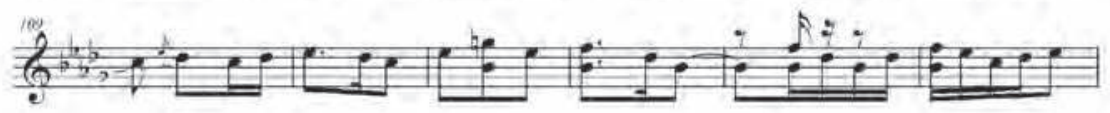

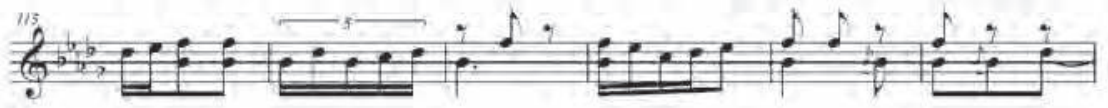

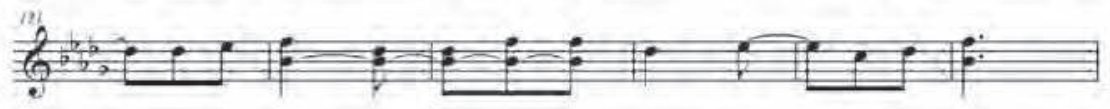
t : :

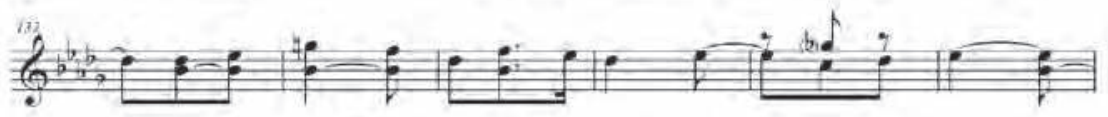

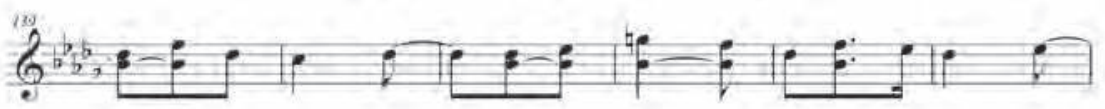



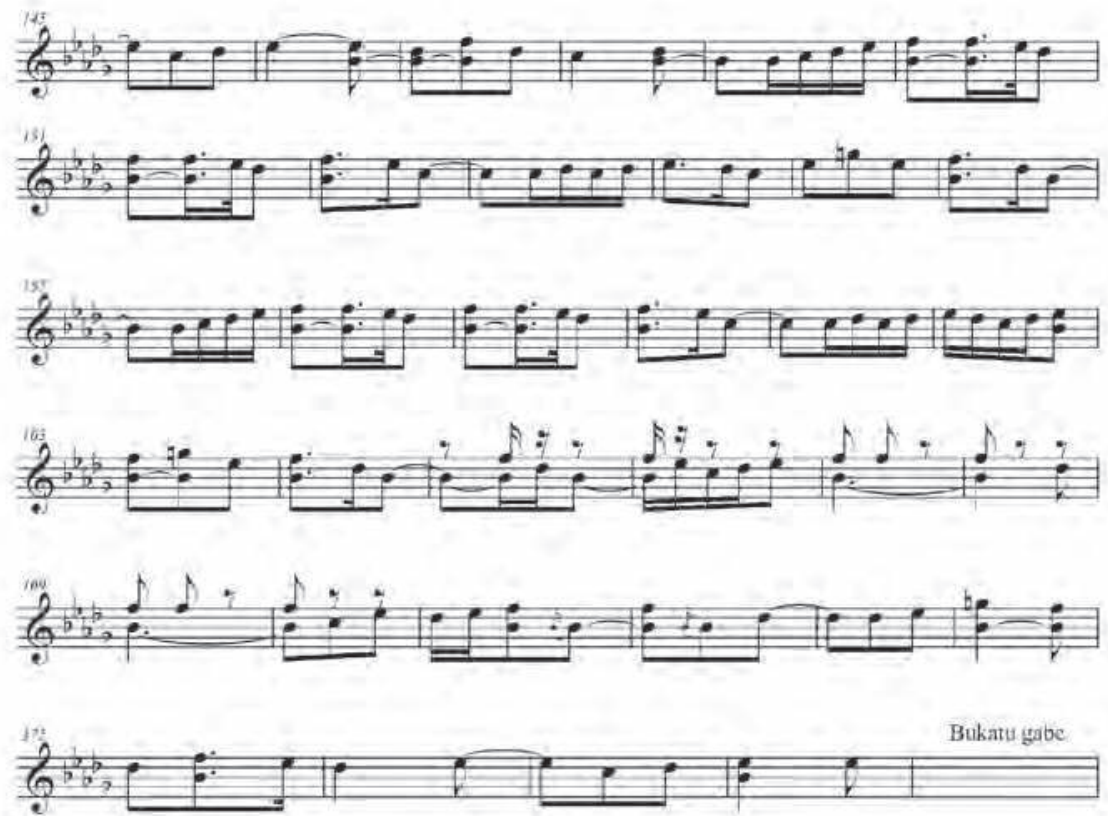

\section{ZILINDROA:}

- «Adios Atsurite» (1 min., 53 seg.):

Ez da ongi entruten.

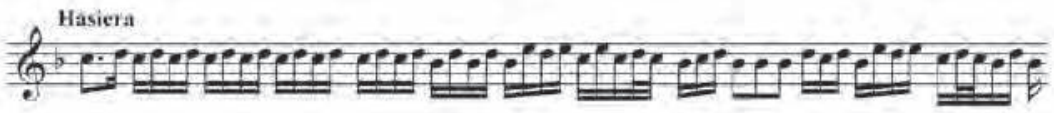

Lati laau ondo anvennaten da:

\section{to $1:$ …ㄹ.}

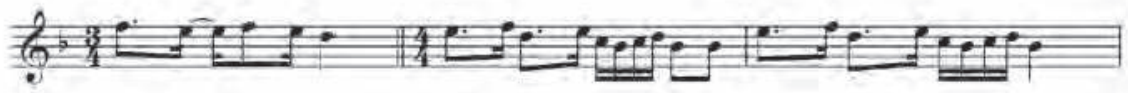




\section{ZILINDROA:}

- «Eztaitarra» (1 min., 1 seg.):

6.

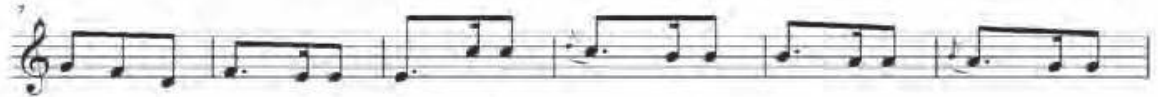

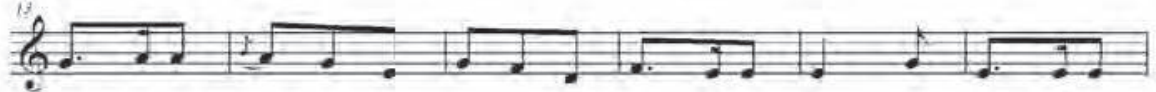

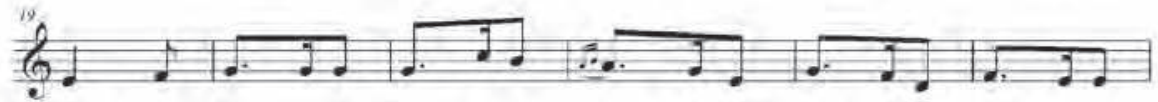

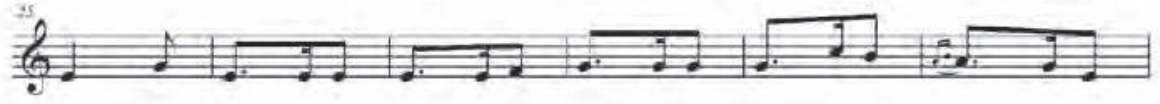
$6 \sqrt{2,5}, 2$.

- «Andre Madelene» (23 seg.):

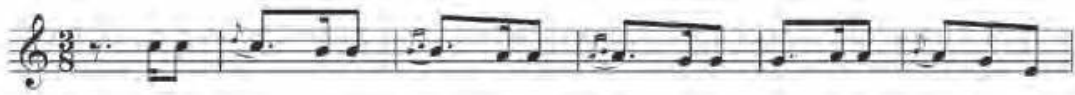

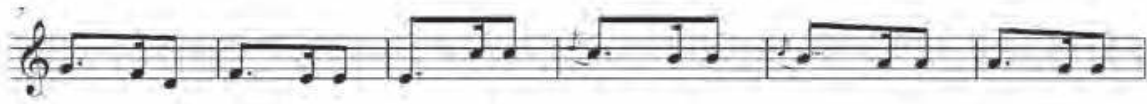

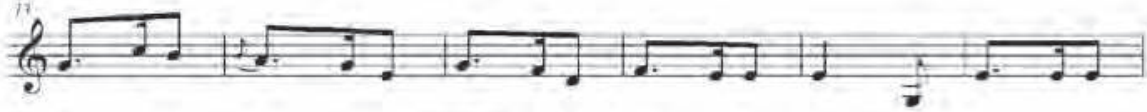

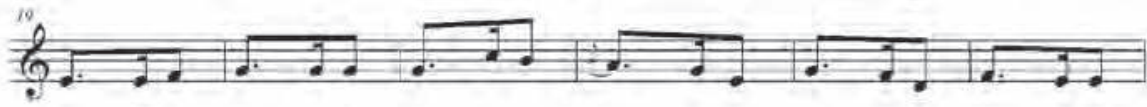
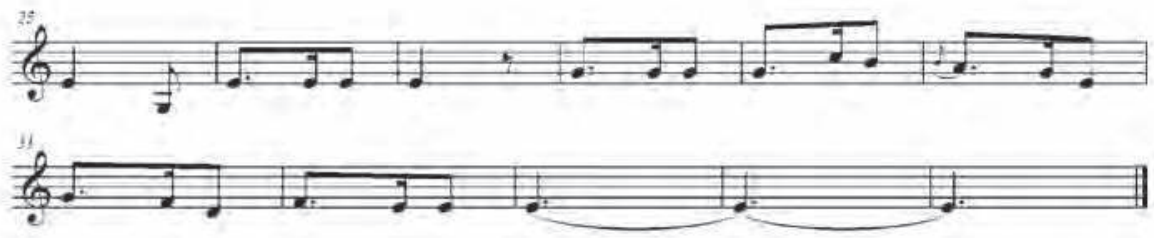
- «Kontsesi» (35 seg.):
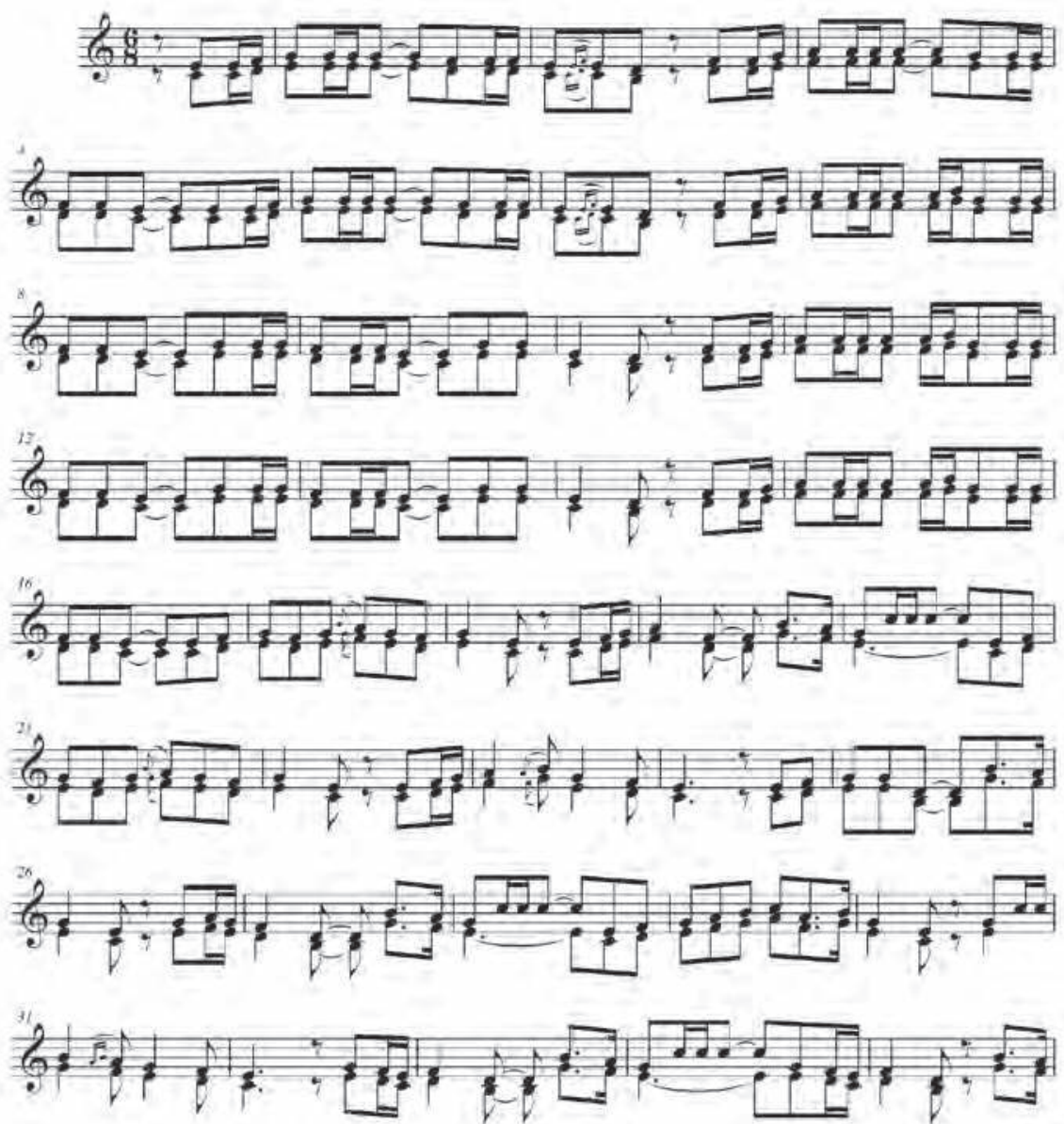

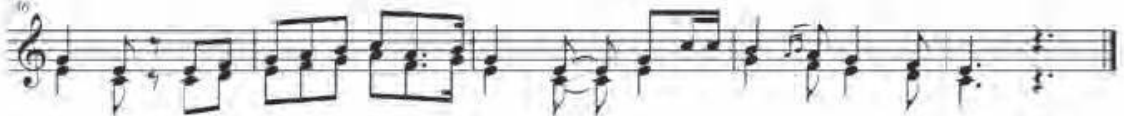


9. ZILINDROA:

- «Baserritarra» (1 min., 12 seg.):

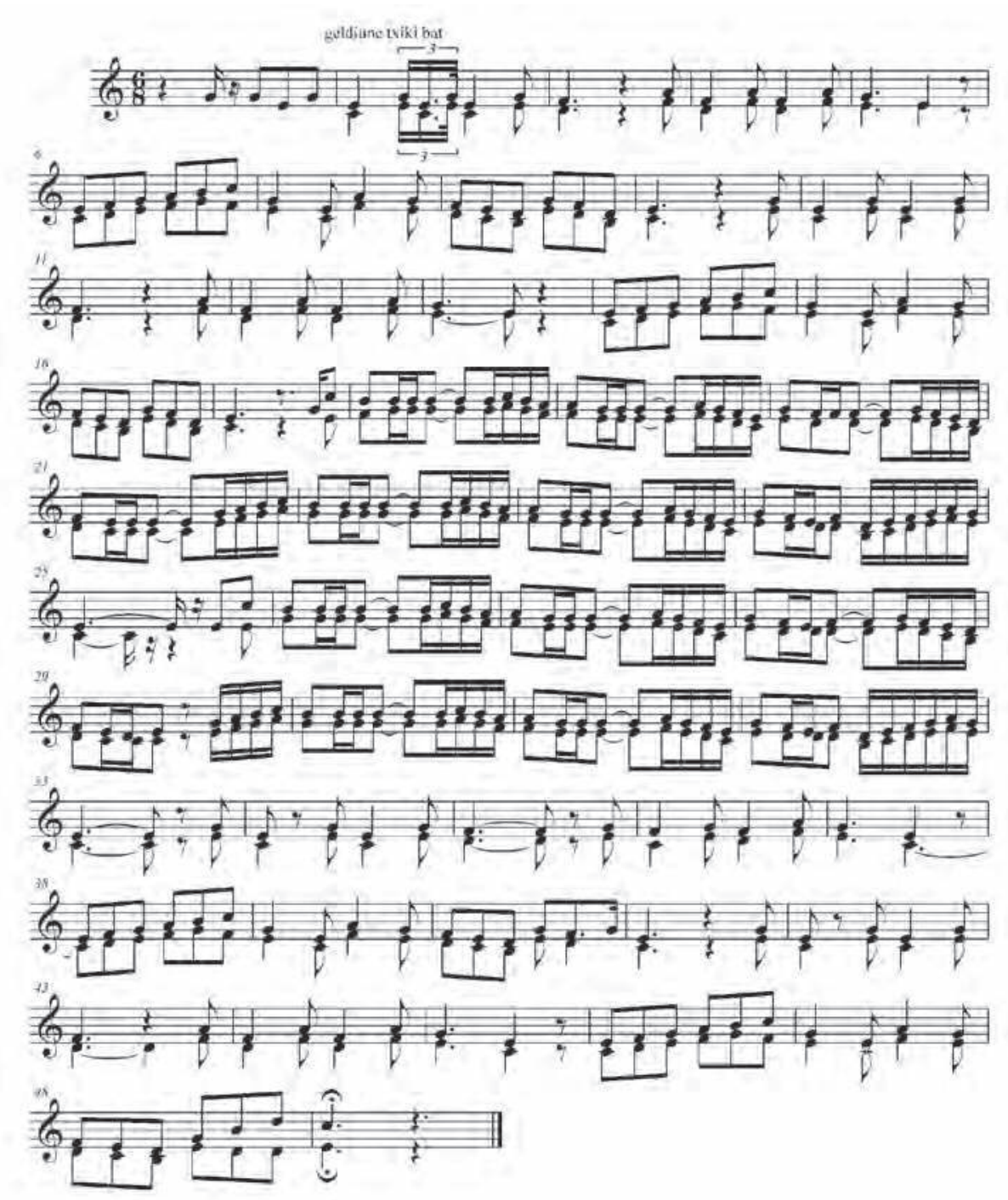


- «Porrusalda: arin-arina» (54 seg.):

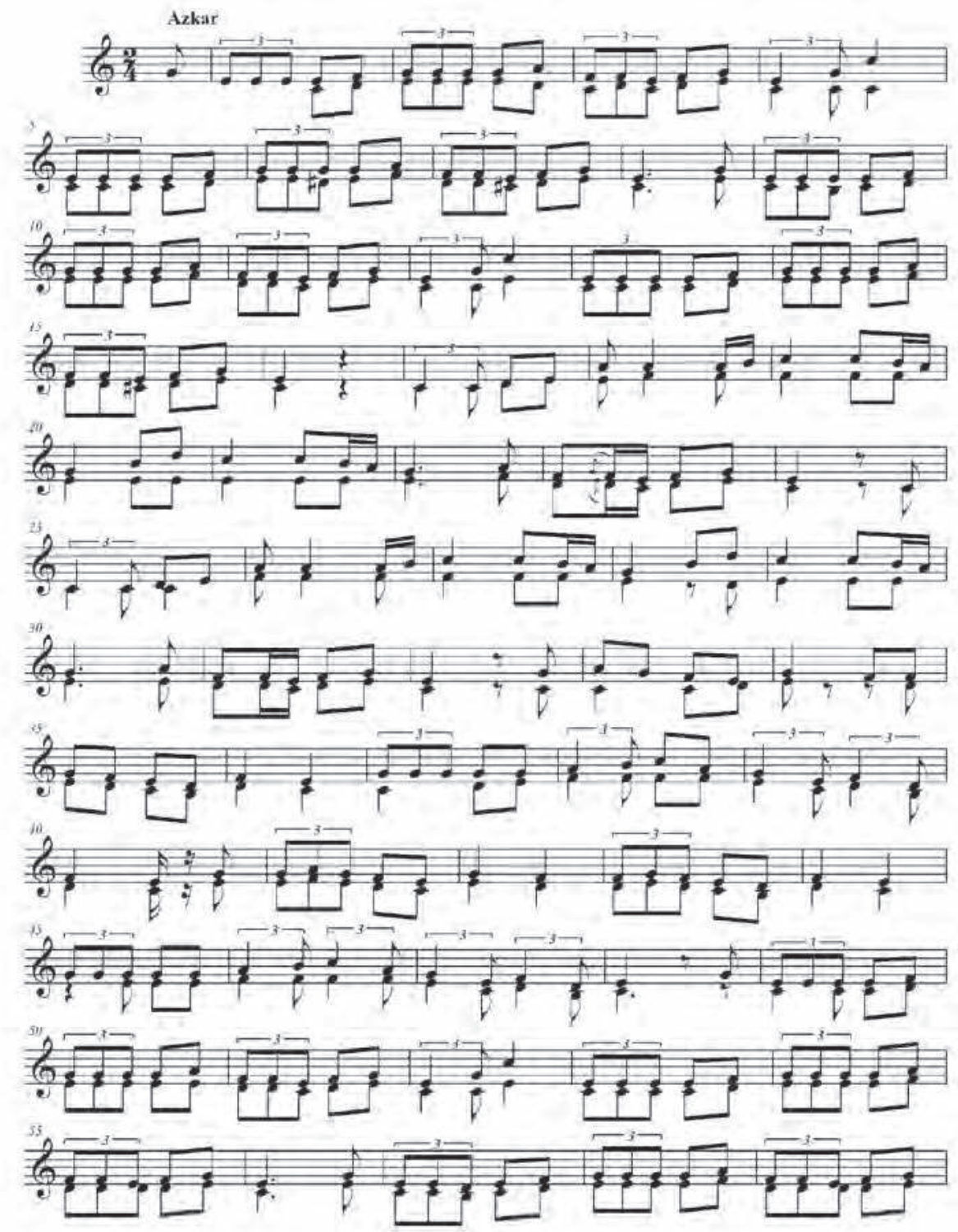




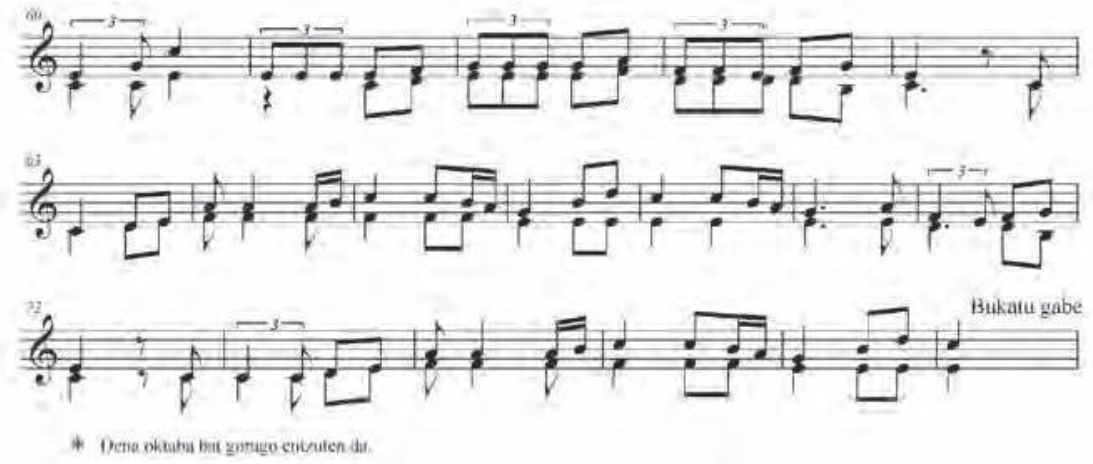

10. ZILINDROA:

- "Vals con variaciones" (2 min., 9 seg.): 


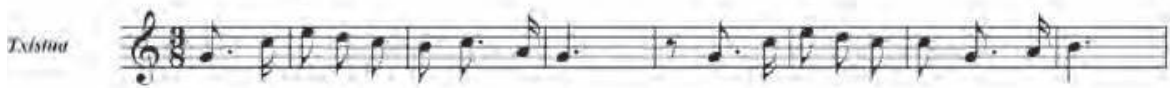

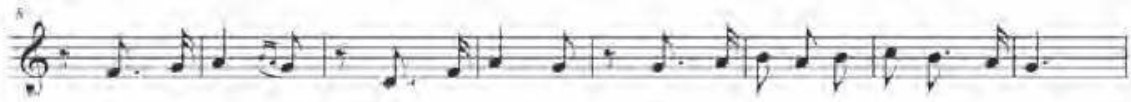

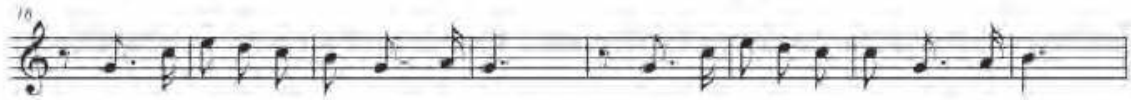

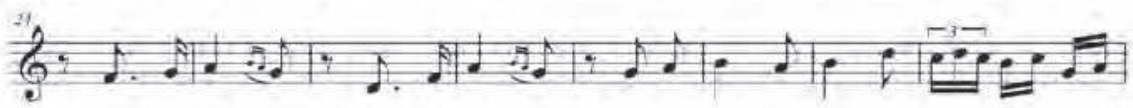

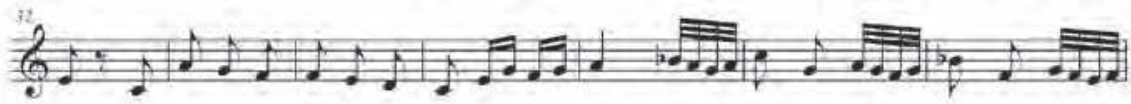

6.

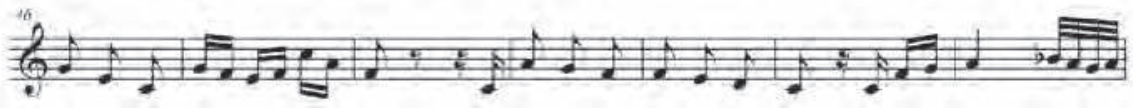

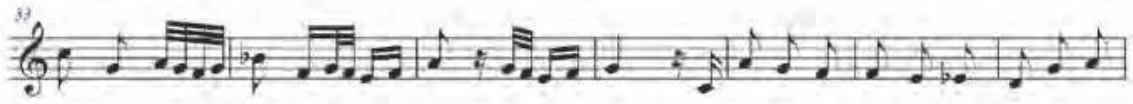

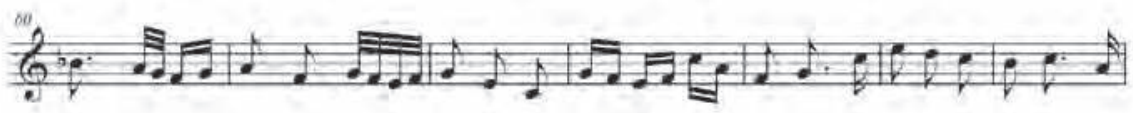

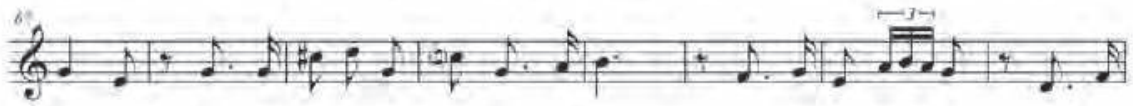

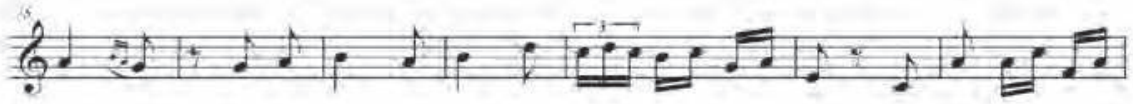

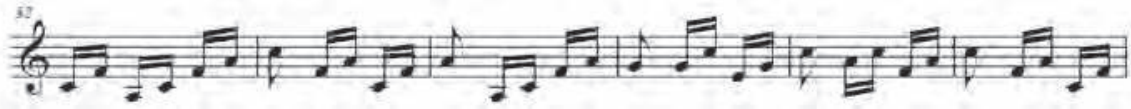



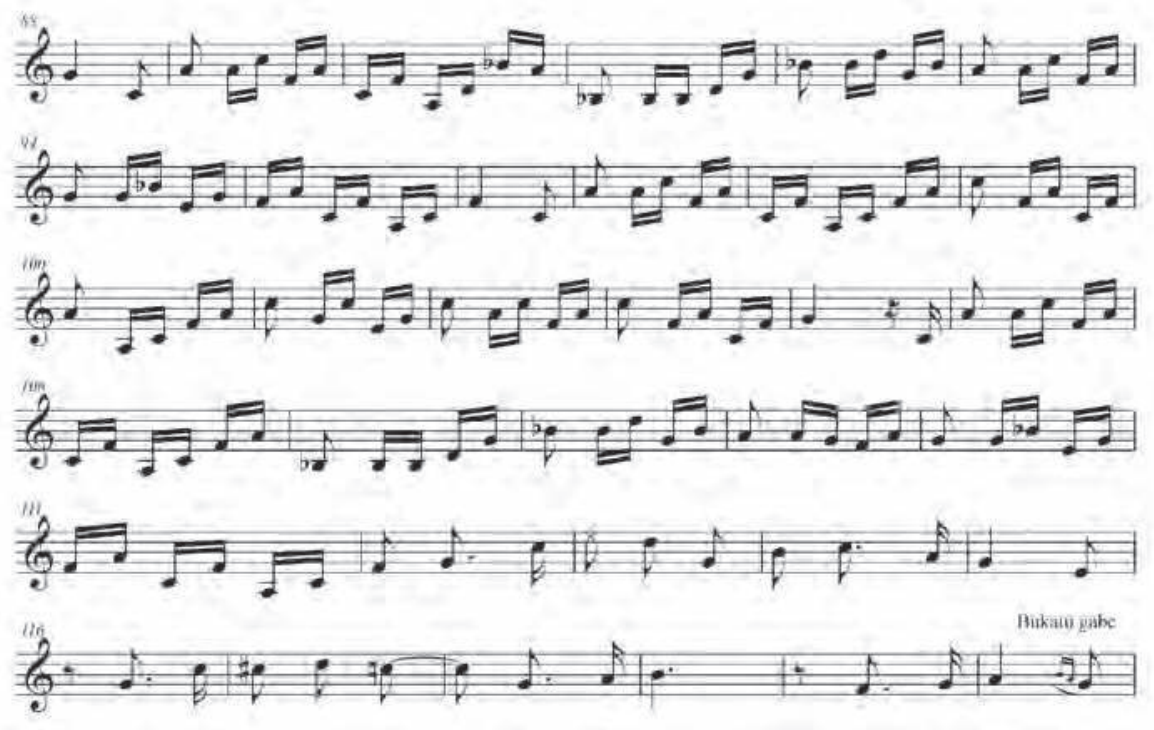


\section{ZILINDROA:}

- "San Juanen Zortzikoa" (2 min., 8 seg):

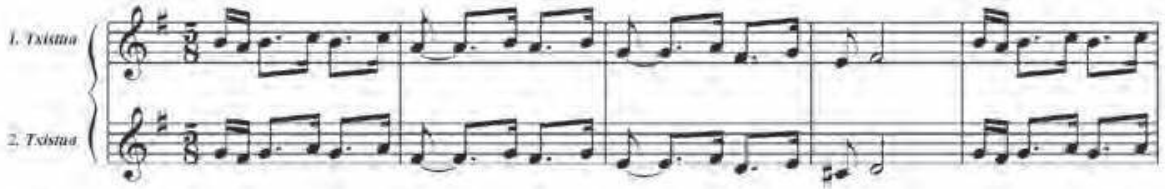

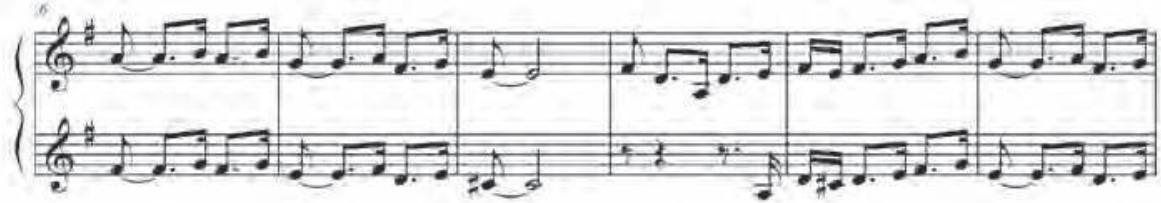
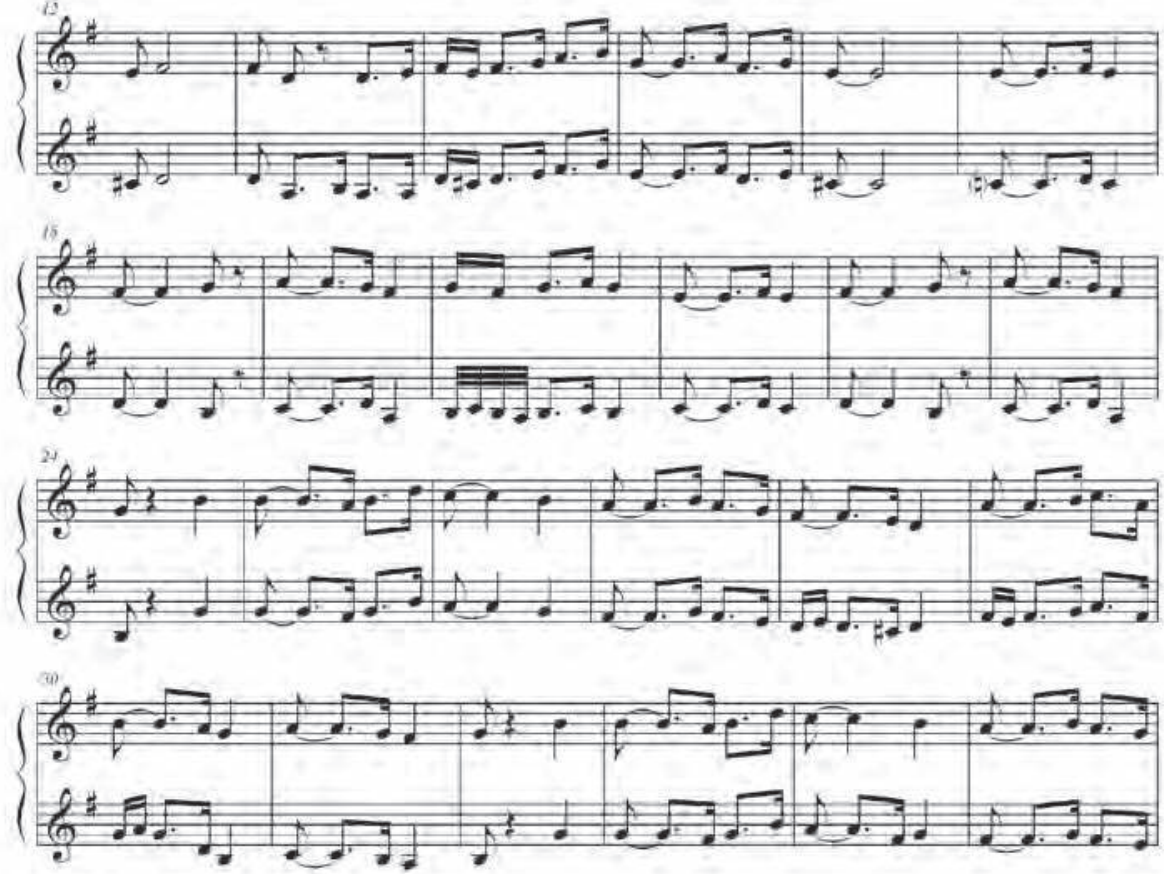
126

INAXIO LÓPEZ DE ARANA ARRIETA
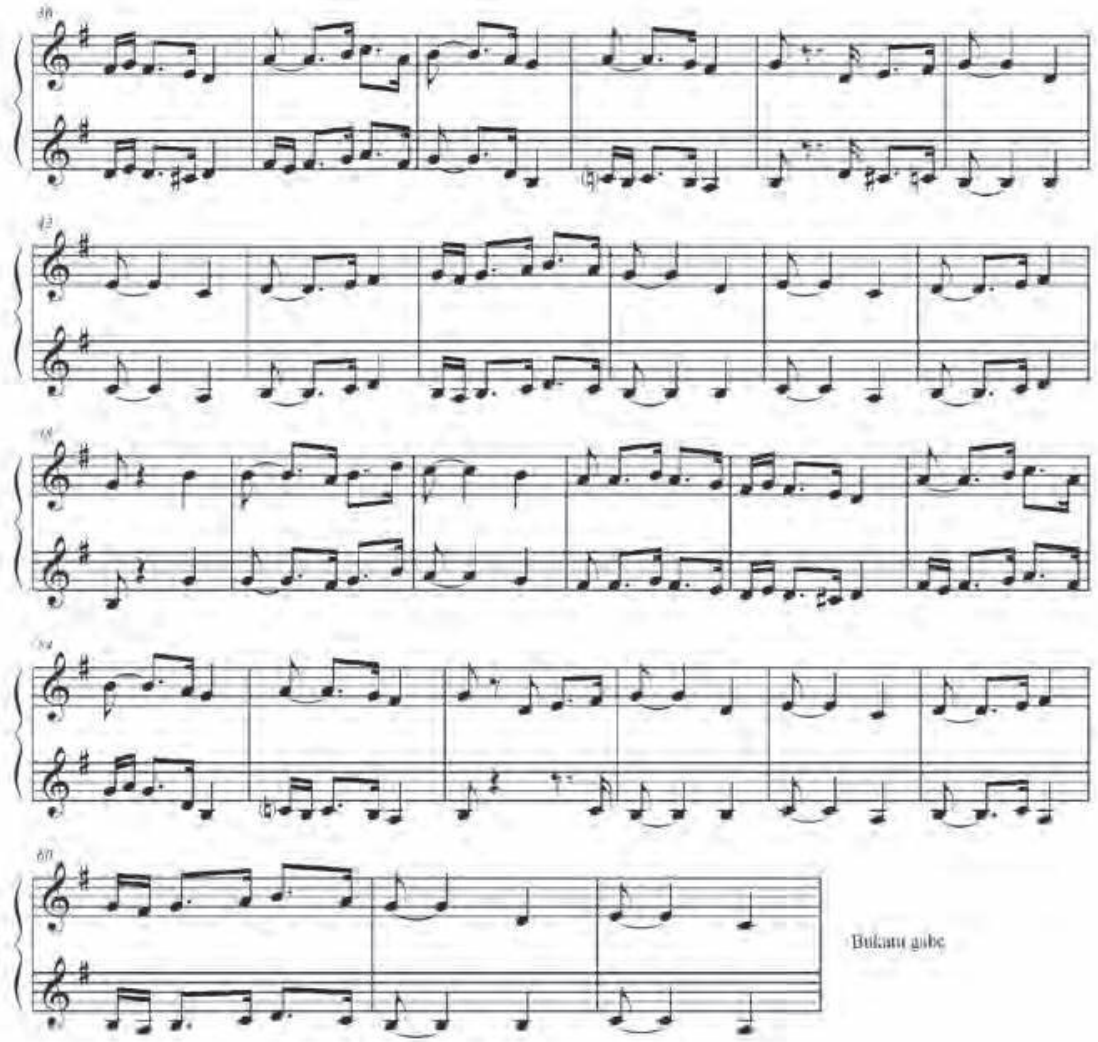


\section{ZILINDROA:}

- «Gernikako arbola» (1 min., 32 seg):

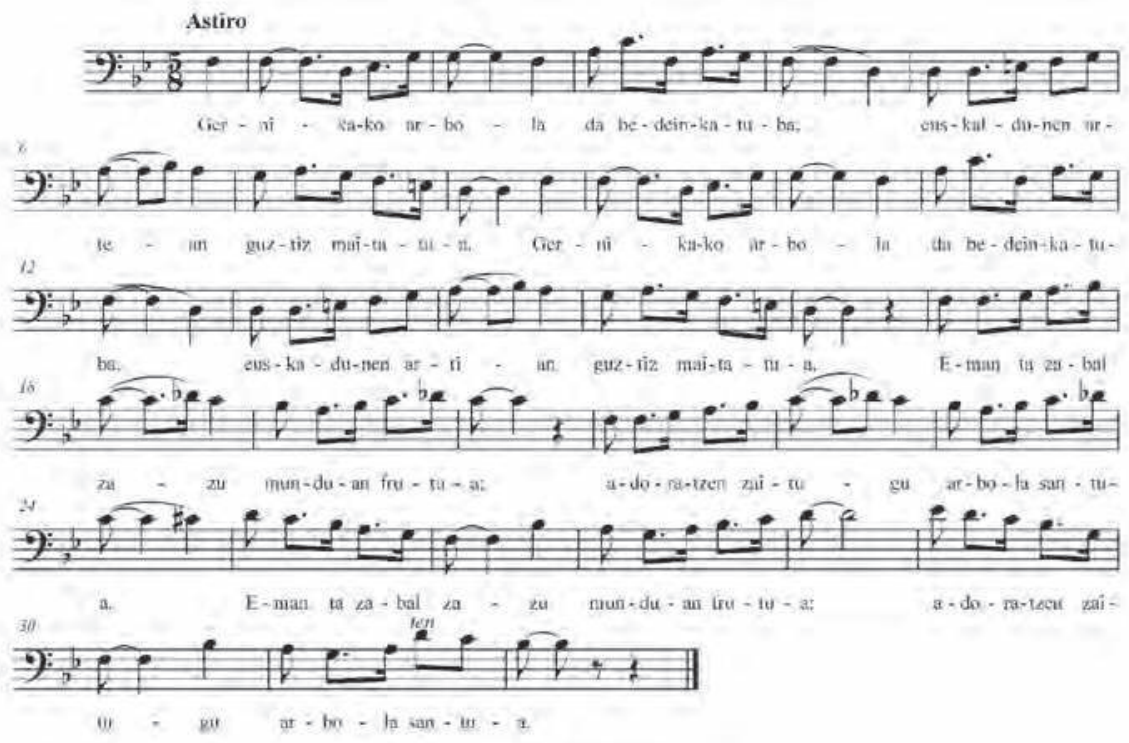

\subsection{DISKOA:}

- «Monein» (1 min., 10 seg.):

Grabaziosren kalitate txarra dela-eta oso zaila da transknpzios taxuz egitea.

Horregatik, zati lau aukeratu dugu:

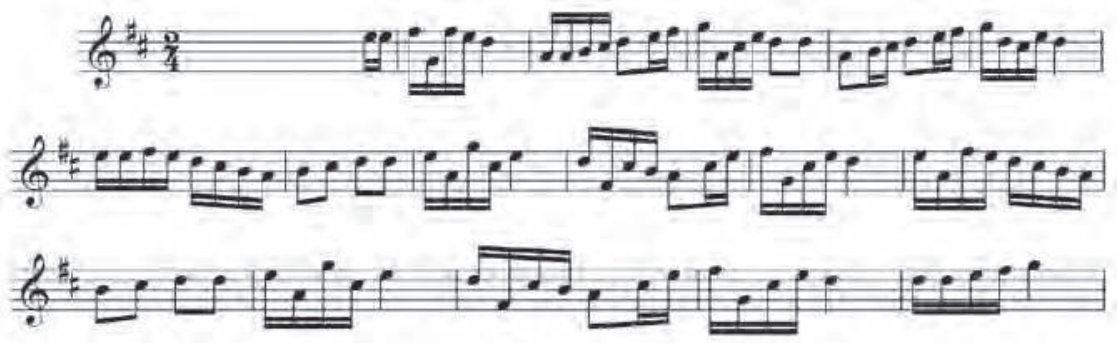




\subsection{DISKOA:}

- «Monein» (1 min., 34 seg.):

Aurreko grabazioaren zailfasum berberak ditu.

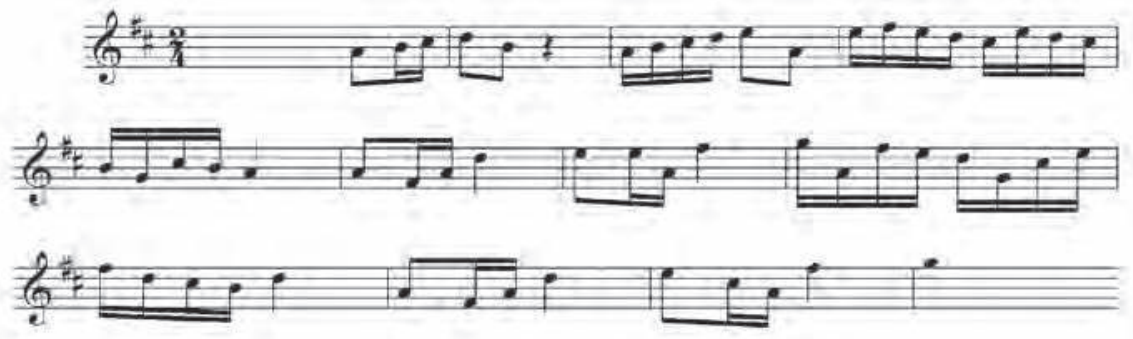


«TREBITSCH BASKEN" EUSKAL SOINUEN BILDUMA

(Rudolf Trebitschek ALEMANEZ idatzitako testua)

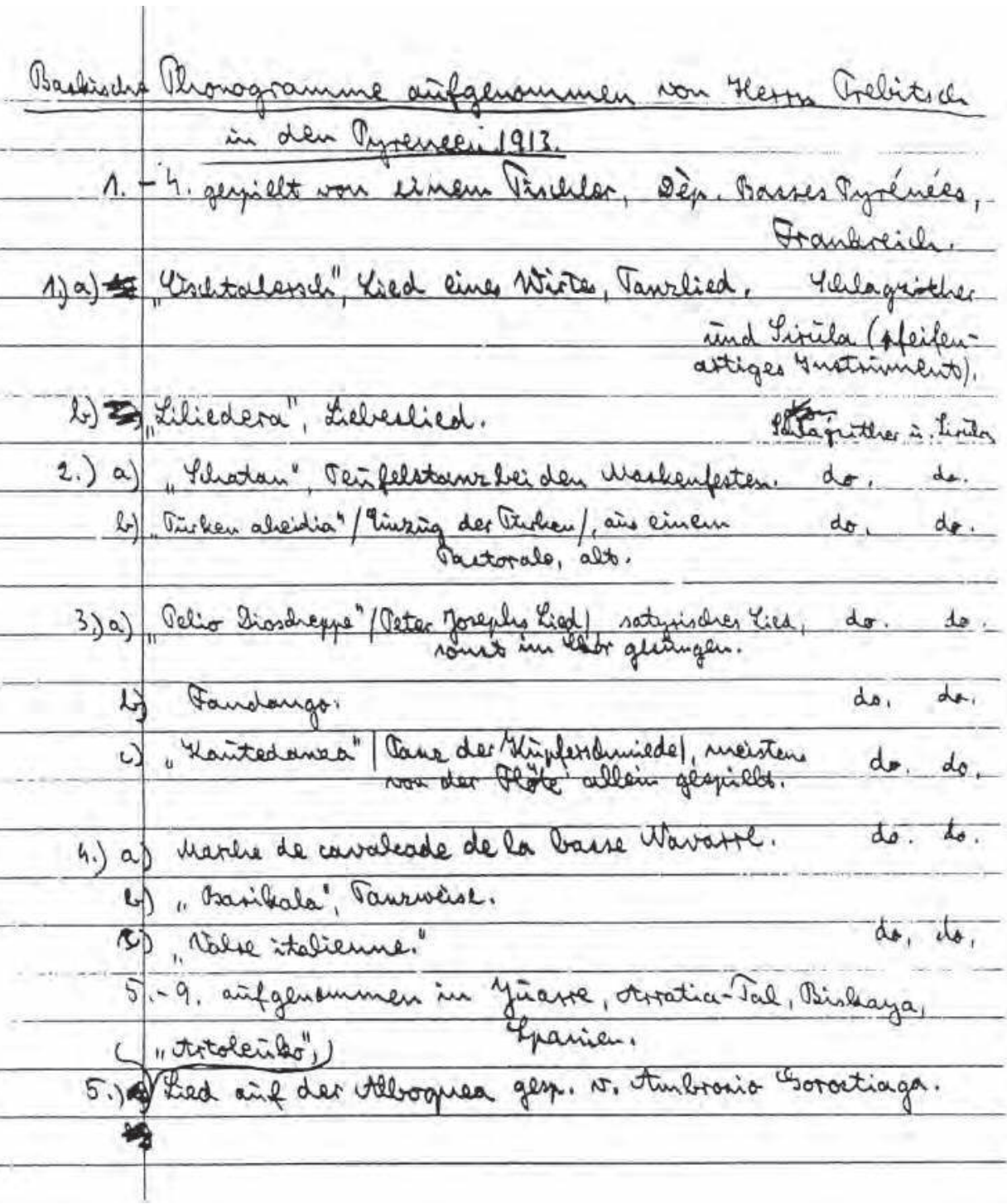


130

INAXIO LÓPEZ DE ARANA ARRIETA

6) Lied aif der colbogiea mit Heandpaibse geop. in. gerimgeu von Jorefor Malo.

7) Fortatising von 6)

8) a) ind b) 2 Dirbaimen is, 1 Cioumel, gerpielt

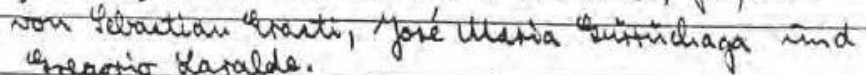
enegatio Kavalde.

a) "Istaitanta" / Hochelitrag/, alter Matsch.

b) "tudrée Madeleive .. Montuenti" (Frainenname), Fanrlied, Fandango.

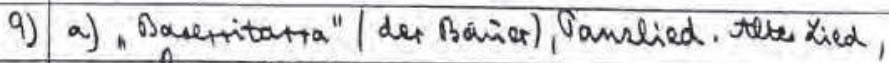
leame wipte.

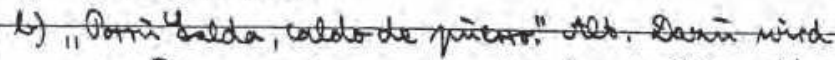
ein Gaur, ations ations" getanst. MLelme Wothe.

a) Buetring wie \&).

10)- 12) aiffgen. in Tolosa, osizinuzcoa, Ypamien.

10) Matsch, gespidts aiff 2 Silvo's ind Tomboril's,

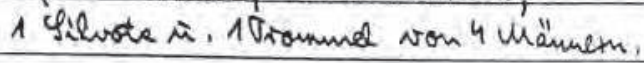

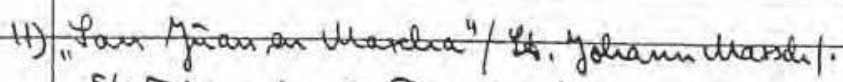
$5 / 8$ Folot, peler alt, Jeact int the

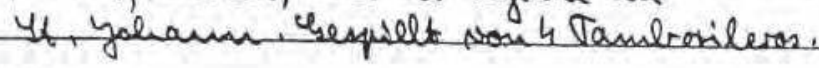

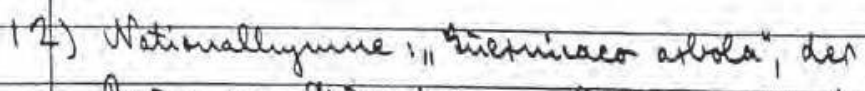

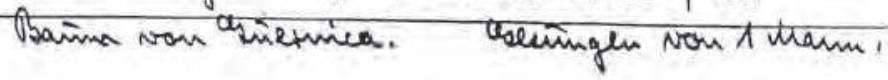




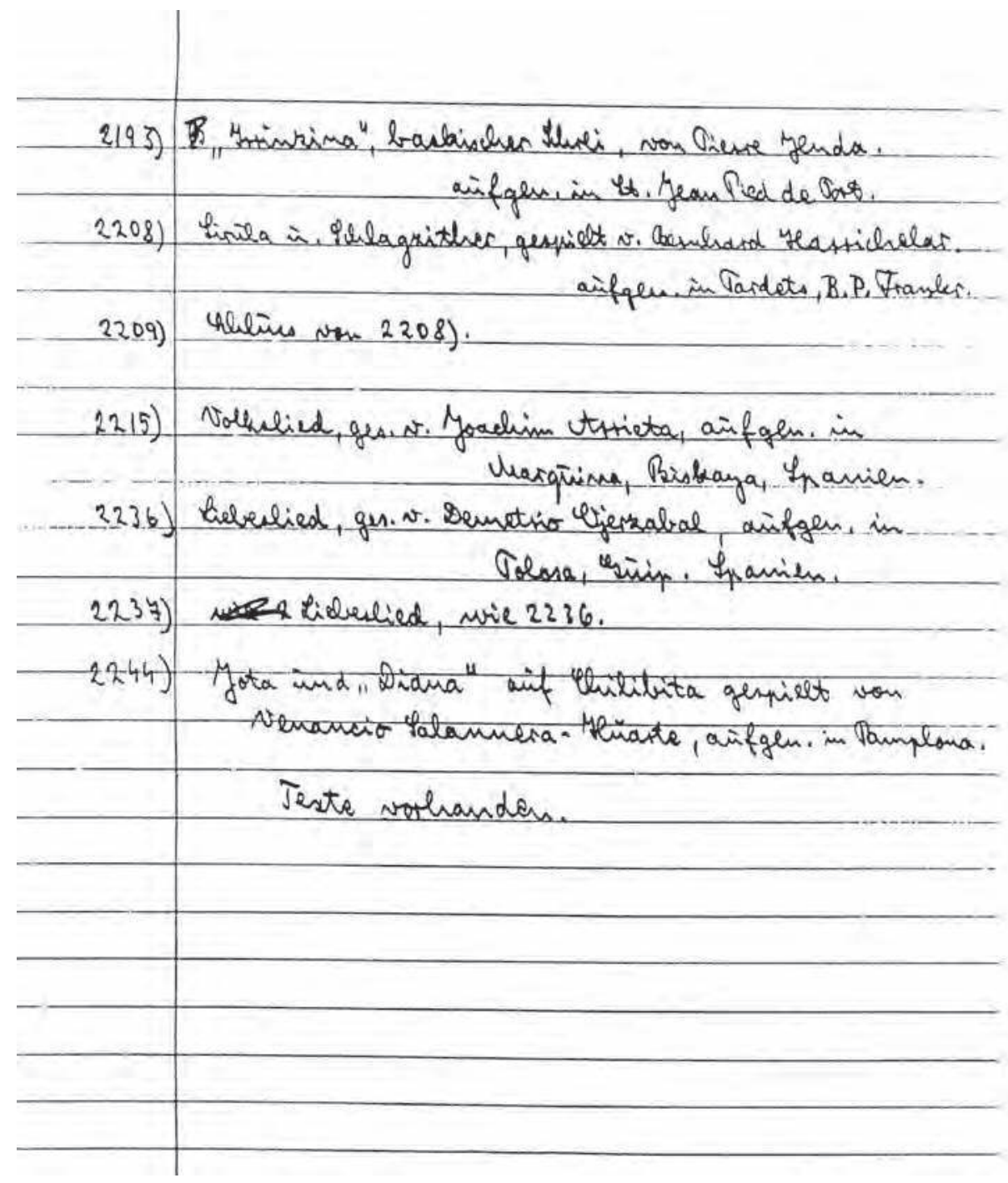




\section{“TREBITSCH BASKEN" EUSKAL SOINUEN BILDUMA}

(Rudolf Trebitschek alemanez idatzitako testuaren euskarazko itzulpena)

\section{EUSKAL GRABAZIO FONOGRAFIKOA, Trebitsch jaunak Pirinioetan 1913an egina}

1-4 Zurgin bat musikari. Pirinio Behereen Departamentua, Frantzia.

1.a) "Ostarlesa", emakumezko ostalari baten kanta. Dantza egiteko kanta. Tuntuna eta txirula (haize-instrumentua).

b) "Lili ederra", maitasun-kanta.

Tuntuna eta txirula.

2.a) "Satan", demonioaren dantza mozorro-jai batean. Tuntuna eta txirula.

b) "Turkiarren sartzea", pastoral batekoa, zaharra.

Tuntuna eta txirula.

3.a) "Pello Joxepe", kanta satirikoa, lagun batzuk batera kantatua.

Tuntuna eta txirula.

b) "Fandangoa". Tuntuna eta txirula.

c) "Kauteren dantza", (galdaragilearen dantza), eskuarki txirula bakarrik erabiltzen da.

4.a) "Nafarroa Behereko Zalditeriaren Martxa".

b) "Barikala", dantza-mota bat.

c) "Italiako baltsea".

5-9 Igorren hartutakoak, Arratia bailaran, Bizkaia, Espainia.

5. "Artolak deuko", Ambrosio Gorostiagak albokaz jotako kanta.

6. Josefa Ealok albokaz eta panderoz jotako kanta. Ahotsa ere Josefa Ealorena da.

7. Seigarrenaren jarraipena.

8. a) eta b) Bi dultzaina eta danbor bat; Sebastián Errasti, José María Gurrutxaga eta Gregorio Larralde ditugu musikariak.

a) "Eztaitarra" (ezkontza-eguna). Antzinako martxa.

b) "Andre Madalen... Kontsesiri". Kontsesi emakume-izena da. Dantza-doinua. Fandangoa. 
9.a) "Baserritarra", dantzatzeko kanta zaharra, letrarik gabea.

b) "Porrusalda". Antzinakoa. Doinu honekin arin-arina dantzatzen da. Letrarik gabe. Bi zatitan banaturik: a) eta b).

$10-12$

Tolosan hartuak (Gipuzkoa, Espainia).

10. Gizon batzuek jotako martxa. Bi txistu eta bi danboril. Silbote bat eta danbor bat.

11. "San Juanen Martxa". 5/8 konpasa. Testua San Juanen ereserkia da. Lau danbolin-jolek dihardute.

12. Ereserki nazionala: "Gernikako arbola". Gizaseme bat kantari.

\subsection{3}

"Irrintzia", euskal garrasia, Pierre Jendak Donibane Garazin egina.

\subsection{8}

Bernhard Haritxelar txirula eta tuntuna jotzen. Atharratze, Pirinio Behereak. Frantzia.

2.209

2.208. aren bukaera.

\subsection{5}

Joaquín Arrietak kantatutako herri-abesti bat. Markina, Bizkaia, Espainia.

\subsection{6}

Demetrio Oiarzabalek kantatutako maitasun-kanta. Tolosa, Gipuzkoa, Espainia.

\subsection{7}

Maitasun-kanta, 2.236.a bezala.

\subsection{4}

Jota dantza eta "Diana", Venancio Salameraren eskutik. Uharte (Iruñea ondoan).

Testu eskuragarriak. 


\section{Argazkiak:}

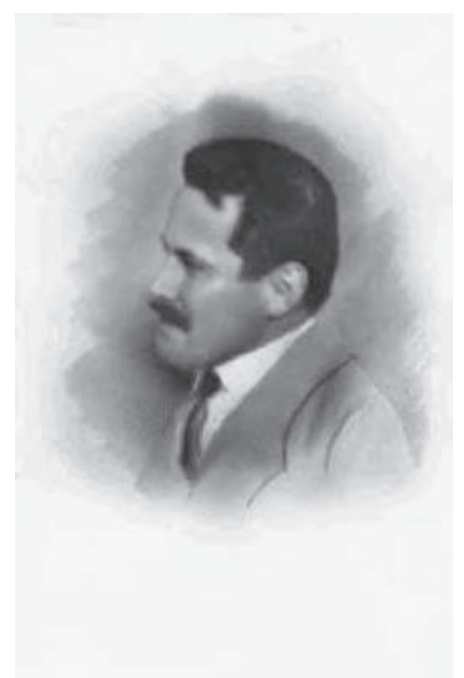

Rudolf Trebitsch

\section{DR-RUDOIF TREBITSCH}

$$
1 .
$$

Baskifiche'Sprach und Aluthauthahment

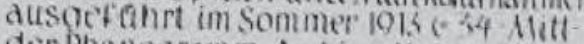
der Phonogram m-Archivs-tiommetion d heth Atidemic d. Wiffenishallen

wien. Wien 1014]

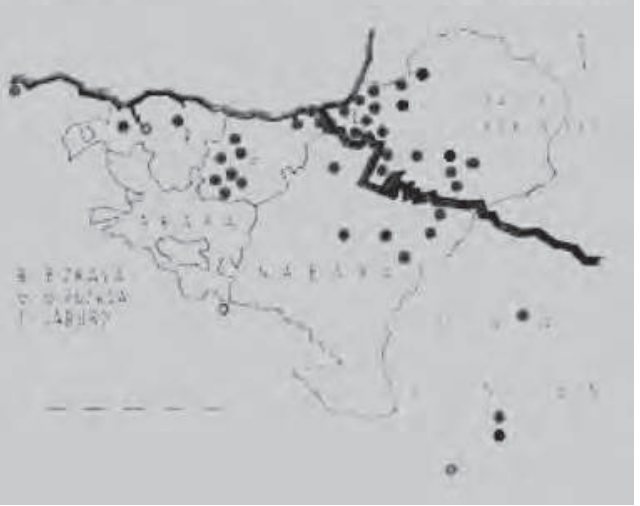

Rudolf Trebitschek Euskal Herrian egindako lanen kartela 


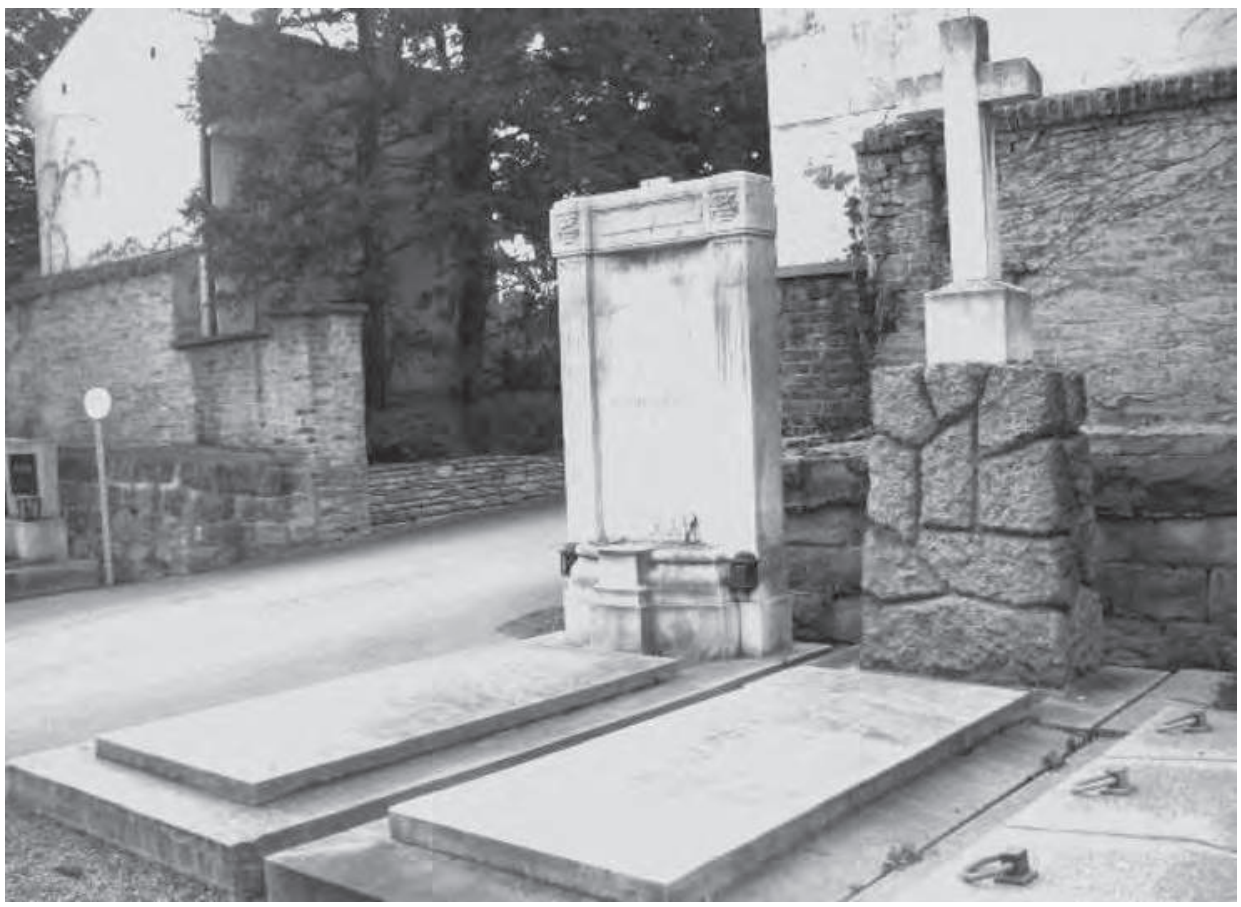

Rudolf Trebitschen hilobia (Hietzing-eko hilerria, Viena) 